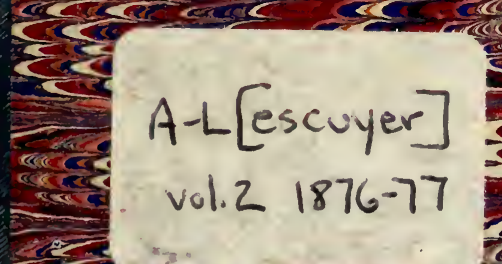

$2 \pi$ coses $<0<0$

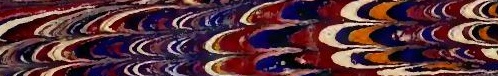

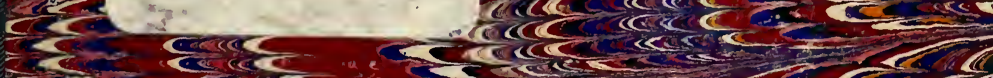

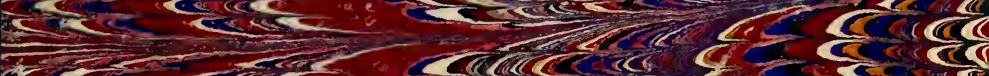

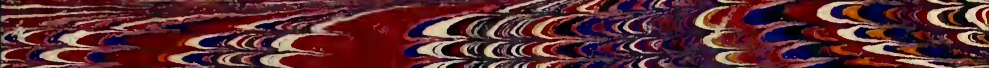

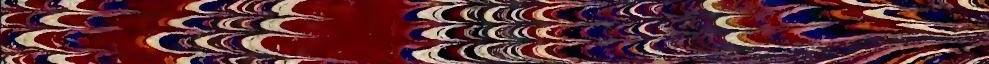

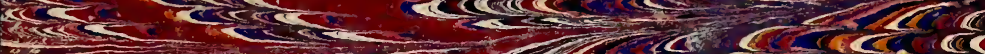

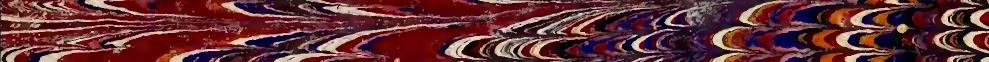

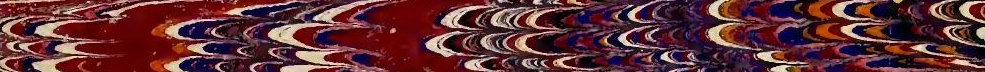

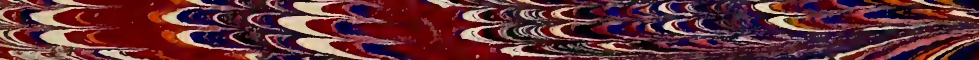

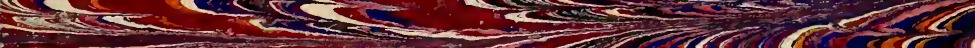

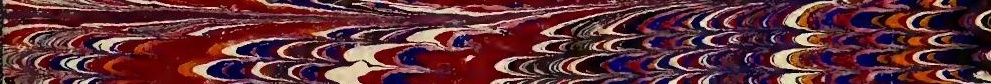

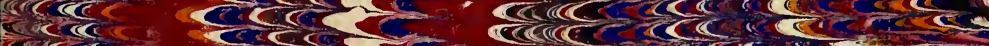

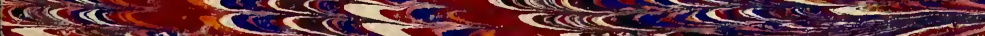
H.

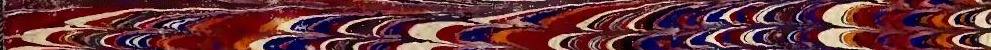

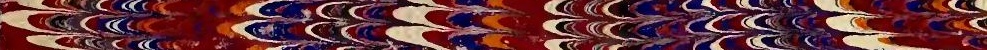

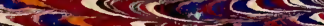

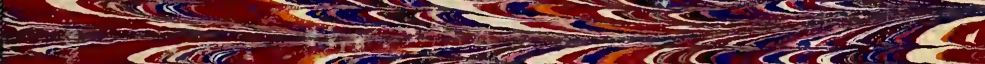

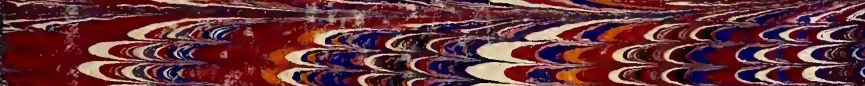

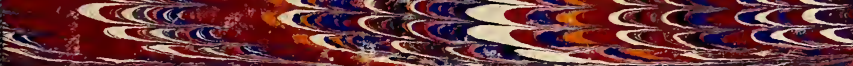

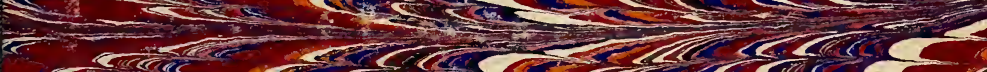

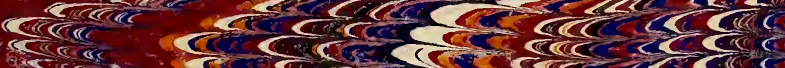

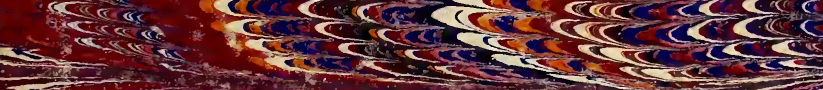

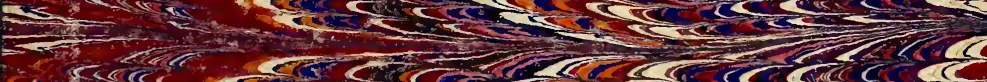

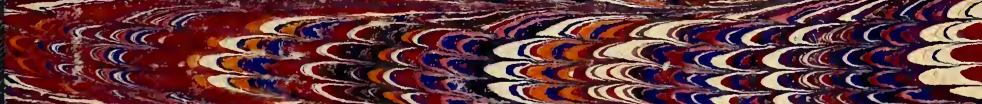

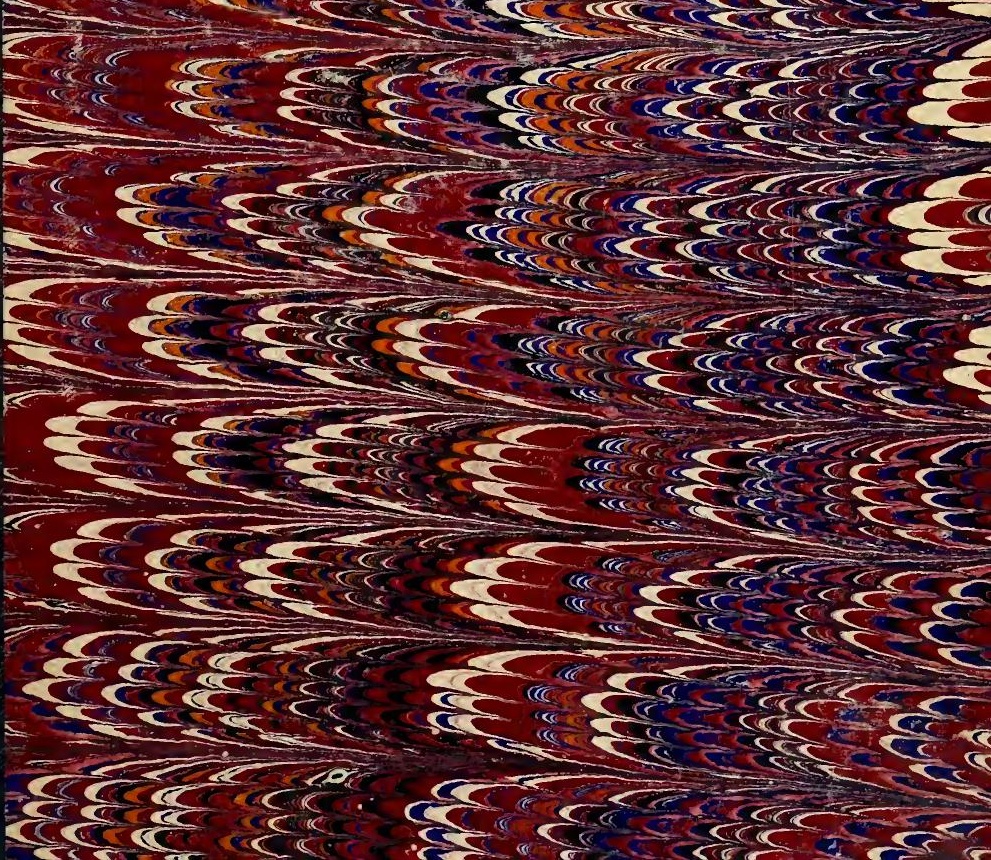




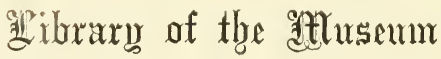
OF

\section{COMPARATIVE ZOÖLOGY,}

AT IIARTARD COLLEGE, CANIBRIDGE, IIASS.

founded by pribate subscription, in 1861.

The gift of $9 . \%$. Alen.

$\lim _{1880}$ No. $7^{546}$ 
- La heronnière d' b'cury.

20. Diseraux de passage.

3o. inclimatation des oiseany 



\section{OISEAUX DE PASSAGE ET TENDUES}





\section{ACADÉMIE DE REIMS - SCIENCES}

MÉMOIRES DE 1874 ET DE 1876

\section{$-\cos 2$ \\ OISEAUX DE PASSAGE ET TENDUES}

\section{PAR M. F. LESCUYER}

MEMbRe TITULAIRE DE L'INSTITUT DES PROVINCES DE FRANCE

ET DE LA SOCIÉTÉ PROTECTRICE DES ANIMAUX, DE PARIS; MLMBIRE CORRESPONDANT DE L'ACADEMME NATIONALE DE REIMS, DF LA SOCIÉTÉ ACADEMIQUE D'AGRICULTURE, DES SCIENCES, ART ET BELLES-LETTRES DE L'AUBE,

DE LA SOCIÉTÉ LINNÉENNE DE MAINE-ET-LOIRE, DE LA SOCIÉTÉ LINNÉENNE DE BORDEAUX,

LE LA SOCIÉTÉ D'AGRICULTURE, COMMERCE, SCIENCES ET ARTS, DE LA MARNE ET DE LA SOCIÉTÉ DES SCIENCES ET ARTS DE VITRY-LE-FRANÇOIS

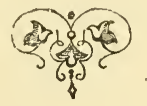

\section{PARIS}

\section{J.-B. BAILLIĖRE ET FILS} LIBRAIRES-ÉDITEURS rue Hautefeuille, 19
VICTOR PALMÉ LIBRAIRE-ÉDITEUR rue de Grenelle-St-Germain, 25

\section{SAINT-DIZIER}

Firmin MARChaNd, Libraire-Éditeur 


$$
\begin{aligned}
& \text { in } y:(1) \mid
\end{aligned}
$$

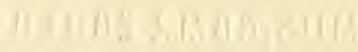

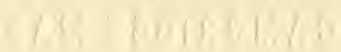


Souscription de M. DE MEAUX

ministre de l'Agriculture, 5 février 18 '76

Rappel de MÉDAILLE D'ARGENT

de la Société protectrice des animaux

de Paris, 17 mai 1875 



\title{
OISEAUX DE PASSAGE ET TENDUES
}

\author{
PREMIERE PARTIE
}

(Mémoire de 1874)

\section{INTRODUCTION}

Doit-on, oui ou non, permettre les tendues aux oiseaux?

C'est là une question encore très-controversée, malgré qu'elle ait été souvent discutée dans les conseils généraux, dans les préfectures, au ministère et par le pouvoir législatif.

Mes recherches ornithologiques m'ayant amené à l'étudier, j'ai trouvé, en faveur de la suppression des tendues, des arguments qui me semblent décisifs.

Je crois, en effet, que ce genre de chasse est contraire à l'intérêt général et à l'esprit de notre législation; c'est ce que je vais essayer de démontrer.

Saint-Dizier, le $1^{\text {er }}$ juin 1873. 

Du droit de chasse.

\section{$1^{\circ}$ DROIT Naturel.}

Au point de vue de la chasse, le droit naturel contient deux principes fondamentaux.

$1^{\circ}$ Nous avons le droit de détruire un animal qui s'attaque à notre personne ou à nos biens et qui, d'une manière permanente, peut causer à la société de graves dommages.

$2^{\circ}$ Il nous est également permis de tuer les animaux sauvages qui peuvent servir à notre alimentation, et par conséquent les oiseaux.

Ces deux libertés doivent être reconnues, mais à la condition qu'elles ne soient pas une cause de restriction pour d'autres libertés, aussi ou même plus précieuses qu'elles.

Ainsi, il est essentiel avant tout de sauvegarder les intérêts de l'avenir, de ne pas tarir les sources de la reproduction par une destruction excessive.

Pour cela il faut réduire par de sages mesures le temps et les procédés de chasse, ce qui a pour conséquence de réduire aussi le nombre des chasseurs.

La société ne doit pas surtout autoriser les prati- 
ques de chasse qui peuvent facilement être cachées, rendre impuissante et illusoire la loi, et dangereuse la surveillance des gardes.

Au nom des intérêts bien entendus de la consommation, on doit détruire peu ou pas du tout les oiseaux serviteurs, c'est-à-dire ceux qui par leurs travaux concourent efficacement à la production de nos richesses.

Tels sont, au point de vue de la chasse, les droits et les devoirs que le poùvoir législatif a à consacrer.

$2^{\circ}$ DROIT FRANÇAIS.

Voyons quelles applications la législation francaise a faites de ces principes, comment nos lois doivent être interprétées et modifiées.

$1^{\circ}$ La loi du 3 mai 1844, qui est la principale et la dernière, apporte quelques restrictions au droit de détruire les animaux malfaisants ou nuisibles.

Elle maintient le droit que conférait la loi du 30 avril 1790 (art. 15̈), celui de repousser et de détruire même avec les armes à feu les bêtes fauves; mais, en ce qui concerne les autres animaux malfaisants et nuisibles, on ne peut employer que les moyens de destruction autorisés par arrèté préfectoral (1), et encore faut-il que ces animaux soient éclarés malfaisants par la même autorité.

(1) Les arrètés sont relatifs au lieu, an mode et aux instruments de destruction. 
L'institution de la louveterie est le complément de ces mesures.

$2^{\circ}$ En quoi consiste le droit de chasser le gibier et quelles restrictions y sont apportées?

Chasser, c'est chercher à s'emparer d'un animal sauvage pour se l'approprier.

La chasse étant devenue un droit inhérent à la propriété, un de ses attributs, on ne peut l'exercer sur la propriété d'autrui qu'autant qu'on en obtient l'autorisation (Loi du 30 avril 1790, art. $1^{\text {er }}$; - loi du 3 mai 1844 , art. $\left.{ }^{\text {er }}\right)$.

On ne devient propriétaire d'un animal sauvage qu'en en prenant le premier possession, d'après l'adage : Res mullius cedit primo occupanti, implicitement rappelé par l'article 715 du C. C. et la loi des 11 août et 3 novembre 1789.

$3^{\circ}$ Sont considérés comme immeubles par destination les oiseaux domestiques au nombre desquels sont compris les oiseaux de colombier et de volière, parce qu'ils vivent, s'élèvent, sont nourris et se reproduisent par les soins et sous le toit de l'bomme (C. C. art. 524 ; arrêt de cassation, 14 mars 1861).

Il est vrai qu'aux termes de beaucoup d'arrêtés de police, les pigeons sortis de leur colombier peuvent être considérés et traités comme des oiseaux nuisibles.

Le droit de chasse a été frappé de divers impêts qui ont eu pour conséquence de réduire le nombre des chasseurs.

Ces impôts sont:

$1^{\circ}$ De $28 \mathrm{fr}$. pour le permis de chasse (Loi des 2 ots mai 1875 );

$2^{\circ}$ De 4 fr. 7à c., de 6 fr. et de 7 fr. 73 c. pour 
les différentes poudres de chasse (Loi du 25 juillet 1873);

$3^{\circ}$ Et de $6 \mathrm{fr}$. pour le chien de chasse (Loi du 2 mai 1855).

En y ajoutant les autres frais indispensables, on trouve que la chasse subit de très-lourdes charges.

La chasse de nuit est défendue (Loi 184.4, art. 9 et 12).

La jurisprudence est appelée à déterminer quel est, d'après les circonstances, le moment précis où commence et finit la chasse de jour.

La chasse ne peut avoir lieu que lorsqu'elle est ouverte par arrêté du préfet. L'ouverture et la clôture de chaque espèce principale de cliasse sont fixécs de manière que la reproduction et la multiplication des animaux sauvages soient assurćes (Même loi, art. 9 et argument).

Les préfets peuvent défendre la chasse pendant les neiges (même loi, art. 9), et ils ont tous pris des arrêtés dans ce sens.

Le permis de chasse donne à celui qui l'a obtenu le droit de chasser à tir et à courre : tel est le principe fondamental en cette matière (Même article).

Les armes secrètes, et particulièrement le fusil à vent, ne sont pas plus permises pour la chasse que pour tout autre usage (Déclar. du 23 mars 1728; décrets des 2 niv. an 14 et 12 mars $1806 ; C$. pén. 314 ; ordonnance 23 février 1837).

La plupart des maires des villes et des villages ont pris des arrêtés pour empêcher de tirer et par conséquent de chasser à tir dans l'enceinte déter- 
minée de la commune, en vertu de l'art. 50 du 14-22 déc. 1789, des art. 3 et 4 du titre XI de la loi du $16-24$ août 1790 , de l'art. 46 , tit. ${ }^{\text {er }}$ de la loi du 19-22 juillet 1791 et de l'art. 11 de la loi du 18 juil. let 1837.

Il est défendu de faire usage de filets pour chasser (loi de 1844, art. 9), si ce n'est pour la chasse du lapin. Dans ce cas, on peut employer les furets et les bourses (id.). A ce sujet une instruction du ministre de la justice porte ce qui suit :

"L'article 9 prohibe d'une manière formelle tous les genres de chasse, à l'exception de la chasse à tir et à courre, et de la chasse au lapin à l'aide de furets et de bourses. Sans faire une nomenclature qui aurait été impossible, il embrasse dans sa prohibition générale l'emploi des panneaux et des filets, avec lesquels on détruisait des volées entieres de perdreaux, l'usage meurtrier des lacets, des collets, et, en un mot, de tous les instruments de destruction, qui ne profitaient qu'aux braconniers ".

L'article 12 de la loi de 1844 complète l'article 9 par les dispositions suivantes: Seront punis d'une amende de 50 à 200 francs, et pourront en outre l'être d'un emprisonnement de 9 jours à deux mois :

$2^{\circ}$ Ceux qui auront chassé pendant la nuit à l'aide d'engins ou instruments prohibés, ou par d'autres moyens que ceux qui sont autorisés par l'art. 9;

$3^{\circ}$ Ceux qui seront détenteurs ou qui seront trouvés munis ou porteurs, loin de leur domicile, de filets, engins ou autres instruments de chasse prohibés ; 
$3^{\circ}$ Ceux qui auront employé des drogues ou appâts qui sont de nature à enivrer le gibier ou à le détruire ;

$6^{\circ}$ Ceux qui auront chassé avec appeaux, appelants ou chanterelles.

Les peines déterminées par le présent article pourront être portées au double contre ceux qui auront chassé pendant la nuit sur le terrain d'autrui et par l'un des moyens spécifiés au paragraphe 2, si les chasseurs étaient munis d'une arme apparente ou cachée.

Par suite des mêmes principes, est également défendue la chasse qui se fait à l’aide de chiens lévriers (arg. de l'art. 9). Cependant la loi a laissé au préfet le droit de l'autoriser (art. 9, $n^{\circ}$ 2). Il est à remarquer que les préfets ne font pas usage de ce droit.

D'après les articles 4 et $12, \mathrm{n}^{\circ} \mathbf{4}$, en temps de chasse prohibée, il est défendu de vendre, acheter, transporter et colporter le gibier.

Enfin, d'après l'article 9, $\mathrm{n}^{\circ} \mathbf{1}$, le préfet peut prendre un arrêté pour prévenir la destruction des oiseaux.

L'instruction du ministre de la justice contient, à ce sujet, l'observation suivante :

“La loi, en prohibant l'usage des filets, a déjà fait beaucoup pour empêcher la destruction des oiseaux, mais cette interdiction peut n'ètre pas toujours suffisante. Les préfets sont autorisés à employer d'autres moyens. Ainsi, ils pourront, s'ils le jugent nẹcessaire, étendre aux œufs et couvées d'oiseaux la défense que le dernier paragraphe de l'art. 9 n'a prononcée qu'à l'égard des nufs et 
couvées de faisans, de perdrix et de cailles ".

Telles sont les différentes prescriptions de la législation française en ce qui concerne la chasse ; il est facile de voir que dans leur ensemble et dans la plupart des détails elles consacrent les principes du droit naturel que nous avons exposés.

\section{$3^{\circ}$ DE LA LÉgislation Relative aUX oiseaux.}

Examinons maintenant l'état de notre législation relativement aux oiseaux. La loi de 1844, art. 9, $\mathrm{n}^{\circ} 1$, contient la disposition suivante :

Néanmoins, les préfets, sur l'avis des conseils généraux, prendront des arrètés pour déterminer :

$1^{\circ}$ L'époque de la chasse des oiseaux de passage, autres que la caille, ainsi que les modes et procédés de cette chasse.

Il en résulte que le législateur a semblé vouloir faire une exception aux règles qu'il a consacrées par un ensemble très-remarquable de dispositions.

Comme cette exception est une dérogation au droit naturel et à la loi française, elle doit au moins être strictement restreinte au cas spécifié dans le paragraphe cité, et il est du devoir d'un préfet, pour rester dans l'esprit de la loi, d'en diminuer autant que possible les applications.

D'abord il reçoit du conseil général un avis et non pas un ordre ; et surtout il n'est pas obligé d'accepter les règlements qui lui sont proposés par ce conseil, autrement il serait dépossédé c̉u pouvoir que lui confère la loi.

Ensuite, l'article 9, $\mathrm{n}^{\circ}$ I, confirme virtuellement 
les principes généraux de chasse en ce qui concerne les oiseaux sédentaires. Le préfet ne devrait pas se croire le droit d'autoriser, à leur égard, d'autre mode de destruction que celui de la chasse à tir.

Chacun sait, au moins d'une manière générale, que nos oiseaux sédentaires sont ceux qui nichent dans nos pays, qui y prennent part aux éliminations si nécessaires de la saison d'été et qui, chaque année, viennent reprendre leur tâche quand ils n'en sont pas empêchés.

Beaucoup de leurs espèces nous fournissent des oiseaux pendant toute l'année.

Ce que nous appelons nos oiseaux de passage sont les sédentaires des autres régions qui passent, en stationnant plus ou moins longtemps dans la nôtre.

Les différentes espèces d'oiseaux sont en effet réparties sur la surface du globe de telle sortequ'elles ont pour leurs opérations un ou plusieurs centres et des rayonnements très-étendus. Le nid est le centre des explorations et des éliminations d'une famille à l'époque de la bonne saison, et cette famille, pendant le reste de l'année, peut transporter son industrie souvent jusqu'aux limites des régions qui sont assignées à son espèce. C'est là ce qu'enseigne l'ornithologie.

En poursuivant cette étude, nous verrons que la chasse à la tendue, mème pour les oiseaux de passage, telle qu'elle s'est faite pendant quelques années dans nos contrées, ne concorde ni avec l'ensemble de notre législation, ni avec l'intérêt général.

L'étendue des terrains affectés par le Créateur à 
chaque espèce des oiseaux sédentaires comprend, en général, un grand nombre de départements, et beaucoup des oiseaux de passage traversent deux fois par an la France du nord ạu sud et du sud au nord. Certains,départements permettant les tendues et d'autres les défendant, il en résulte une choquante inégalité devant la loi, une attribution inégale des droits de chasse?par rapport à la propriété.

Ensuite, si pendant qu'un département s'efforce de protéger certains oiseaux, comme ètant des agents très-utiles à l'intérêt général, un département voisin néglige de prendre ce soin, ou mème autorise à perfectionner l'art de les détruire pour un intérêt très-particulier, il en résulte un état de choses pour lequel certainement les hommes ne se sont pas constitués en société.

Ces anomalies sont d'autant moins justifiables, que depuis quelques années cinq départements se permettent les tendues, quand tous les autres les proscrivent, et que de la sorte une infime minorité se constitue une espèce de monopole.

Pour le moins, la loi aurait dû ne pas jermettre à un préfet d'autoriser les tendues dans son département, sans l'avis favorable des conseils généraux des départements limitrophes.

En ces matières, un département est à l'état d'enclave parrapport aux départements qui l'entourent, et il eût été juste qu'on lui appliquât, $a u$ moins de cette manière, un principe consacré par la jurisprudence et d'après lequel est condamné un chasseur qui tend dans son clos, quand la tenduc n'est pas autorisée dans son département. 
De l'insuffisance de la loi et surtout de la condescendance du ministre de l'intérieur, il est résulté que le département de la Meuse a recommencé à autoriser les tendues. La Meurthe, les Vosges, la Haute-Marne, le Vaucluse ont suivi cet exemple. Pourquoi tous les autres départements ne feraientils pas de même, ne serait-ce que pour montrer ce qu'il y a de défectueux dans ces détails de notre législation?

Poursuivons. Si l'impôt de la chasse s'explique, c'est surtout quand on se donne le luxe de vivre de rossignols, de rouges-gorges, de fauvettes à tête noire, de troglodytes, de roitelets. Ces chasses n'ont cependant à supporter ni l'impôt du chien, ni celui de la poudre. Ne serait-il pas plus juste qu'elles supportassent un surcroît de charges proportionnelles aux priviléges dont elles jouissent, surtout à une époque où tous les impôts sont si aggravés? De plus, pendant que le maître chasse à tir ou à courre, le soin de la tendue est souvent confié à des manœuvres, à des domestiques, à des femmes, à des enfants âgés de moins de 16 ans, et même à des gardes.

En fait, sinon en droit, il suffit d'avoir plusieurs manœuvres pour avoir plusieurs tendues.

Il résulte de là un permis de chasse collectif, qui protége des enfants, des gardes, ce qui consacre à la fois plusieurs illégalités.

Pour que la tendue donne de bons résultats, les chasseurs demandent et l'autorité accorde quelquefois une priorité d'ouverture.

En général, on peut tendre sans bruit, en cachette et sans se faire remarquer. On est souvent à 
la tendue aux premières et aux dernières lueurs du jour, c'est-à-dire, quand pour la jurisprudence il fait nuit.

Les engins restent même constamment tendus.

Le braconnier n'a plus à craindre qu'on saisisse chez lui des lacets, puisqu'ils sont autorisés pour les tendues.

De cette façon, la surveillance devient très-difficile pour les gardes et quelquefois dangereuse, ef la loi reste sans sanction.

Dans les tendues faites en conformité de l'arrêté du préfet, on ne relâche pas la perdrix, ni la bécasse qui s'est prise dans le lacet.

Et surtout on prend aussi bien et mieux encore les oiseaux sédentaires que les oiseaux de passage, c'est même par ceux-là que l'on commence, co qui est tout à fait contraire à l'esprit et à la lettre de la loi.

En supposant, par impossible, qu'ils soient protégés dans le département où ils ont été sédentaires pendant la période des pontes, ils pourront être sacrifiés le jour où ils quitteront le pays natal, parce qu'alors ils deviendront des oiseaux de passage.

Et cependant les grandes migrations périodiques ont pour résultat la vérification, la rectification et le complément des travaux exécutés par les oiseaux sédentaires, et c'est grâce à ce merveilleux mécanisme, que les oiseaux parviennent à enrichir des bienfaits de l'élimination toutes les contrées qu'ils visitent.

En résumé, parmi les oiseaux, il en est qui nous sont extrêmement utiles comme ouvriers et comme 
artistes, et c'est contre eux seuls qu'on a étendu le droit de chasse.

Il nous semble donc que la tendue estla négation du droit, le renversement des principes ; non-seulement elle n'est pas en harmonie avec l'ensemble de nos lois, mais elle est manifestement contraire à l'intérêt général ; c'est ce que nous allons chercher à développer.

\section{II.}

Statistique des tendues.

Une tendue en 1832. - Dans la Haute-Marne, à la limite de la Meuse, il existe un petit bois séparé de 丂̆ à 6 kilomètres des grandes forêts ; il a en longueur environ 3 kilomètres et en largeur 2 kilomètres. Dans le sens de sa longueur, il s'étend du sud-est au nord-ouest. En 1832, la partie nord de ce bois, sur une étendue des deux tiers environ de la surface totale, était en taillis de 3 à 10 ans; alors on pratiqua à la lisière de ces taillis un sentier qui avait environ 1,500 mètres de long sur 1 mètre de large. On l'entretenait soigneusement et on le balayait. On y plaça 1,500 raquettes et 400 lacets; les raquettes étaient à deux mètres les unes des autres et sur deux rangées chacune d'un côté du sentier. Les lacets étaient disséminés dans toute la longueur au milieu de la voie. En septembre, on amorçait quelques raquettes avec des grains de raisin.

Cette tendue dura du 15 août au $1^{\text {er }}$ octobre.

Le préposé à la tendue, employé d'une grande 
maison, faisait deux tournées par jour, la $\mathbf{1}^{\text {ro }}$ de 7 à 9 heures du matin, la $2^{\text {e }}$ de 5 à 7 heures du soir ; il était considéré comme manœuvre et n'avait pas de port d'armes : celui de son maître seul suffisait.

On prit en moyenne, chaque jour, 15 oiseaux par cent raquettes, c'est-à-dire au total 22\%, plus 10 oiseaux dans les 400 lacets.

Chaque soir, on avait donc en moyenne 235 oiseaux; une même personne, en 45 jours, arriva ainsi à en détruire 10,575.

On prenait les trois quarts des oiseaux sur la lisière du nord-est, et un quart seulement sur celle du sud-ouest. La tournée du matin fournissait les deux tiers des prises de la journée; elles étaient abondantes dans les lieux où les insectes se manifestaient en grand nombre. Sur les 10,575 oiseaux, il y en avait environ 9,000 de petite taille ou de très-petite taille, beaucoup de rouges-gorges, de rouges-queues, de roitelets, ensuite des pouillots, des fauvettes, des rossignols, des torcols, des sittelles, peu de pinsons, de bruants et de chardonnerets, etc.

Le surplus était composé d'oiseaux de moyenne taille, tels que grives, merles, gros-becs, pics, geais ; c'est surtout en septembre que se prenaient la plupart des gros oiseaux.

On ne détruisit ni oiseaux de proie, ni corbeaux, ni étourneaux, mais au moyen de lacets on captura des perdrix grises, des perdrix rouges et des bécasses.

Les oiseaux étant pris par le pied, ils étaient à peu près tous vivants quand on venait les décrocher. 
Des dix-neuf cents baguettes dont étaient faits les raquettes et les lacets, les trois quarts étaient en coudrier.

Cette tendue se continua pendant sept ans, de 1832 à 1839. Dans les dernières années, elle donna des résultats moins considérables.

J'ai également eu connaissance de quelques autres tendues faites de 1840 à 1850 , dans des sentiers à la lisière des bois ou à l'abreuvoir. On m'a cité un propriétaire qui à lui seul avait 3,000 raquettes.

J'ai visité beaucoup de tendues qui étaient bien plus modestes; dans toutes, les faits signalés cidessus se reproduisaient à peu près de la même manière; seulement on prenait moins d'oiseaux qu'en 1832.

Les années 1871 et 1872 ont offert un intérêt parficulier au point de vue des tendues.

En 1871, les pontes n'ont pas réussi, et de plus le nombre des oiseaux était sensiblement diminué depuis quelques années. Au contraire, la végétation vigoureuse de $\mathbf{1 8 7 2}$ favorisa la multiplication des insectes ; sous les mêmes influences de température, les pontes d'oiseaux donnèrent leur maximum. Il en est résulté que les tendeurs n'ont pas réussi en 1871, mais qu'en 1872 ils ont pris beaucoup d'oiseaux.

Il faut le remarquer, de temps en temps, des années aussi favorisées que celle de 1872 viennent rétablir, dans le monde des éliminateurs, l'équilibre qui semblait devoir disparaître.

Pour ces différentes raisons, je crois donc uile de résumer les états de trois tendues faites pendant 
ces deux années, sur trois points fort différents de la Meuse et de la Haute-Marne.

Dans la crainte d'abuser de la patience de quelques lecteurs, je m'abstiens de produire tous les faits secondaires, et cependant bien intéressants, de ces tendues; il me suffira, je l'espère, pour les édifier, d'en présenter un petit nombre.

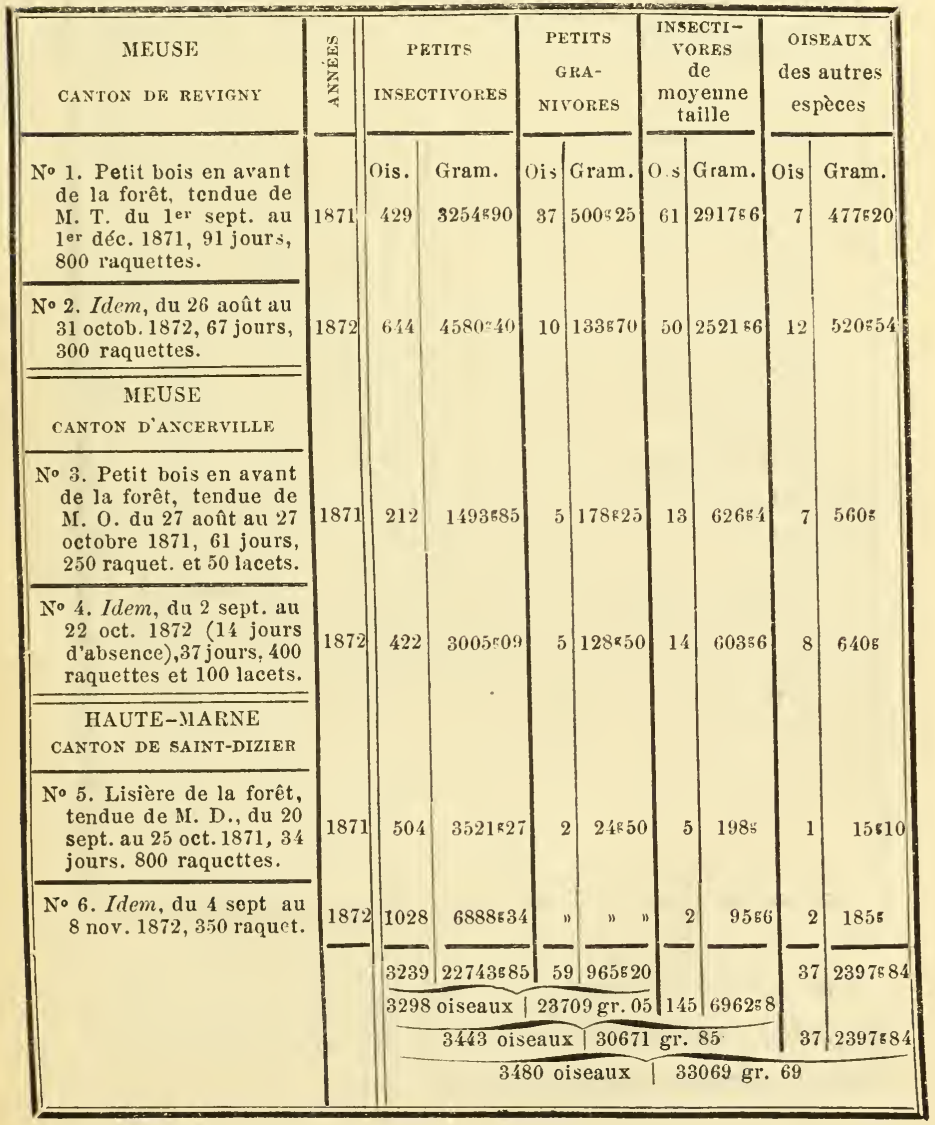


Voici le nombre, les espèces et le poids de la chair des oiseaux de la tendue $\mathrm{N}^{\circ} 2$, en 1872.

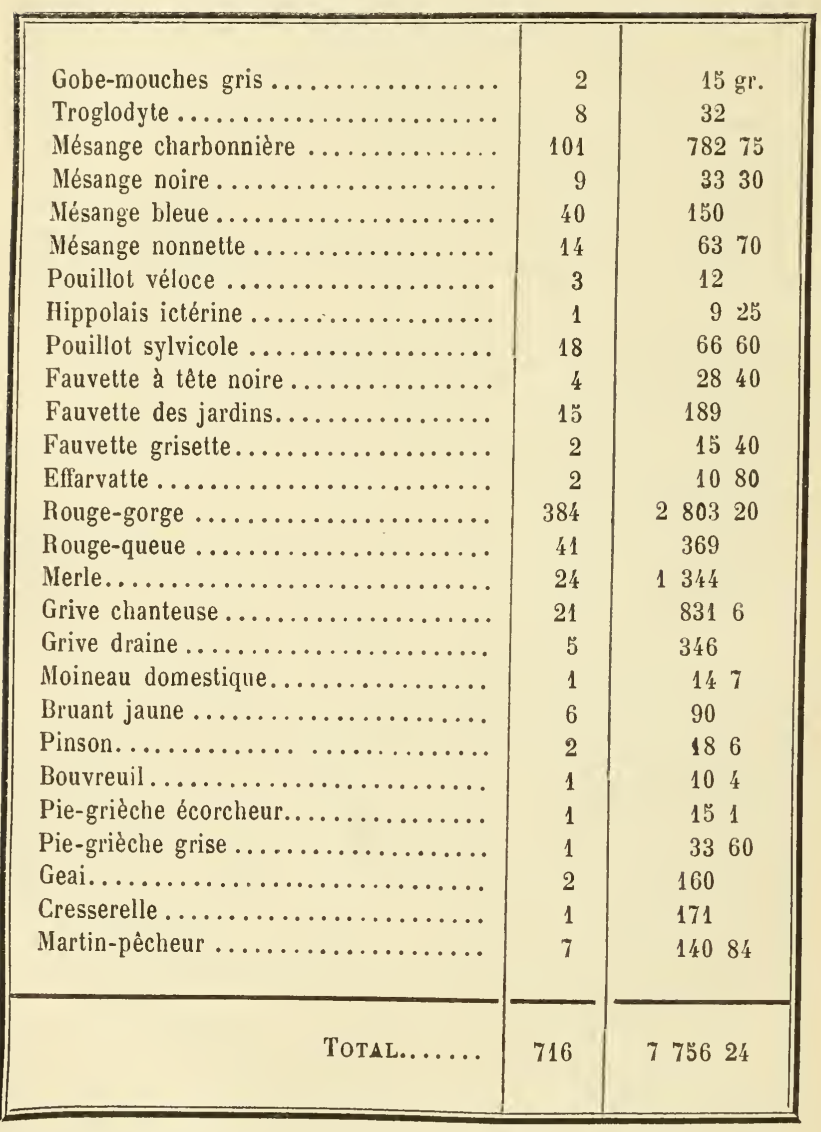

On pourra encore, par le tableau suivant, se faire une idée exacte des divers oiseaux pris dans les six tendues ci-dessus mentionnées : 


\begin{tabular}{|c|c|c|c|c|c|c|c|}
\hline \multirow{2}{*}{$\begin{array}{c}\text { NOMS } \\
\text { DES OISEAUX }\end{array}$} & \multicolumn{6}{|c|}{ TENDUES } & \multirow{2}{*}{ : } \\
\hline & $n^{\circ} 1$ & $n^{\circ} 2$ & $n^{\circ} 3$ & $n^{\circ} 4$ & $n^{\circ} 5$ & $n^{\circ} 6$ & \\
\hline Gobe-mouches gris.. & 9 & 2 & $"$ & ") & ” & ") & 11 \\
\hline Pipit des arbres.... & 1 & $"$ & $n$ & " & $n$ & 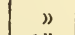 & 1 \\
\hline Troglodyte......... & 12 & 8 & 10 & ") & 11 & 45 & 86 \\
\hline Roitelet moustache...... & 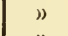 & 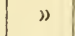 & $"$ & ") & 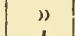 & 1 & 1 \\
\hline Roitelet huppé .......... & $"$ & $n$ & $"$ & 2 & 1 & 2 & 5 \\
\hline Mésange charbonnière.... & 10 & 101 & 20 & 20 & 45 & 51 & 247 \\
\hline Mésange noire........... & 1 & $\begin{array}{llllll} & 9\end{array}$ & ” & $"$ & 11 & 8 & 29 \\
\hline Mésange bleue ......... & 14 & 40 & 13 & 27 & 15 & 36 & 145 \\
\hline Mésange nonnette........ & 3 & 14 & 4 & 3 & 9 & 5 & 38 \\
\hline Mésange à longue queue.. & 7 & ") & 3 & 2 & 4 & 6 & 22 \\
\hline Pouillot fitis $\ldots \ldots \ldots \ldots$ & $"$ & $"$ & $"$ & $"$ & ") & $"$ & ") \\
\hline Pouillot véloce......... & 3 & 3 & $"$ & $"$ & $n$ & 18 & 24 \\
\hline Pouillot sylvicole.. & 9 & 18 & 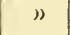 & 8 & 1 & 9 & 45 \\
\hline Hippolais ictérine........ & ") & 1 & $"$ & $"$ & $"$ & ") & 1 \\
\hline Accenteur........ & 4 & $"$ & $"$ & ” & $"$ & " & 4 \\
\hline Fauvette à tête $n$ & 1 & 4 & 1 & $n$ & ) & ” & 6 \\
\hline Fauvette des jardins ..... & 16 & 15 & 1 & $"$ & $"$ & ” & 32 \\
\hline Fauvette babillarde....... & " & 2 & " & ” & $"$ & ” & 2 \\
\hline Fauvette grisette......... & 9 & $"$ & ” & $n$ & ” & " & 9 \\
\hline Effarvatte............ & 9 & 2 & $m$ & $"$ & ” & ") & 11 \\
\hline Rouge-gorge........... & 208 & 384 & 143 & 329 & 391 & 479 & 1934 \\
\hline Rossignol.............. & 7 & 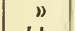 & 2 & 1 & ) & $\nu$ & 10 \\
\hline Rouge-queue........... & 104 & 41 & 15 & 25 & 11 & 11 & 207 \\
\hline lepot........ & 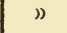 & ” & " & 5 & $"$ & 1 & 6 \\
\hline$\ldots \ldots$. & ") & $"$ & " & $"$ & 》 & 1 & 1 \\
\hline Pic-épeiche............ & 1 & $"$ & ) & $\because$ & $"$ & » & 1 \\
\hline$\ldots \ldots \ldots \ldots \ldots$ & 2 & $"$ & ) & ) & 5 & 1 & 8 \\
\hline$\ldots$. & 27 & 24 & 5 & 3 & » & 1 & 60 \\
\hline Grive chan & 32 & 21 & 7 & 11 & 5 & 1 & 77 \\
\hline Grive draine $\ldots \ldots \ldots \ldots$. & 2 & 5 & 1 & $"$ & " & $"$ & 8 \\
\hline . $\ldots \ldots \ldots \ldots$ & 7 & ” & ") & " & ") & ” & 7 \\
\hline a domestique...... & 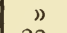 & 1 & $"$ & ) & » & ) & 1 \\
\hline Bruant jaune........... & 22 & 6 & ) & ") & ) & ) & 28 \\
\hline Pinson.$\ldots \ldots \ldots \ldots \ldots$ & 4 & 2 & $"$ & 1 & ” & ” & 7 \\
\hline d'Ardennes........ & 1 & " & $"$ & 1 & 2 & 》 & 4 \\
\hline Bouvreuil... & 3 & 1 & ) & " & $"$ & ) & 4 \\
\hline Pie-grièche écorcheur.... & 2 & 1 & ” & ") & 1 & 》 & 4 \\
\hline ie-grièche grise ........ & ) & 1 & ") & " & ” & 》 & 1 \\
\hline 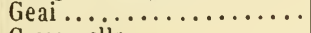 & 3 & 2 & 7 & 8 & ” & 1 & 21 \\
\hline elle............. & 1 & 1 & $"$ & " & $"$ & ") & 2 \\
\hline artin-pêcheur.......... & $"$ & 7 & $"$ & ") & $"$ & ) & 7 \\
\hline Gros-bec.............. & $"$ & $n$ & 5 & 3 & " & ) & \\
\hline \multicolumn{7}{|c|}{$\begin{array}{l}\text { Insectivores de petite et de très-petite taille de la tendue } \\
n^{\circ} 6 \text {, dont les espèces n'ont pas été déterminées, par } \\
\text { suite d'une absence du tendeur ordinare............... }\end{array}$} & 356 \\
\hline & \multicolumn{6}{|c|}{ TOTAL GÉNÉRAL........... } & 3481 \\
\hline
\end{tabular}


A ces états de tendue, je pourrais en ajouter d'autres qui ont été également et consciencieusement ¿tablis, mais ils n'en diffèrent pas sensiblement. Je me contente d'en signaler les particularités qui peuvent avoir de l'intérêt pour la science et la législation.

D'abord, et il est bon de le mentionner, dans beaucoup de pays, et dès le $1^{\text {er }}$ août, de rusés braconniers font des tendues volantes; dans les jours de sécheresse surtout, ils vont camper leurs lacets autour d'une fontaine, d'un ruisseau, d'une eau croupissante, vers lesquels affluent les grives, les merles, les pics, les tourterelles, les ramiers ; aussi prennent-ils relativement plus de gros oiseaux que les tendeurs munis d'un permis de chasse.

Souvent ces braconniers vont furtivement visiter les grandes tendues, y décrocher les oiseaux et même prendre les lacets et les raquettes.

Voici quelques faits qui prouvent qu'il y a moins d'oiseaux qu'autrefois.

En septembre 1819, M. X. a pris dans une tendue de š0 lacets, en un jour, 7 pics-verts.

Le 2 novembre 1820, un tendeur, II. D., a attrapé, avec 150 lacets tendus autour de quelques mares d'eau, 99 gros oiseaux et 2 sittelles ; à part 11 geais, ces oiseaux étaient des merles, des grives chanteuses et des grives mauvis.

Le 16 octobre 1826, un autre tendeur a capturé,

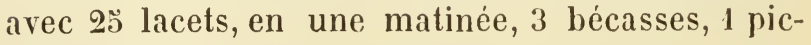
vert, 2 merles, 2 grives chanteuses et 1 geai.

De vieux tendeurs de tous pays m'ont dit que dans leur jeunesse il y avait beaucoup plus d'oiseaux que maintenant; aussi, dans la tendue dont l'état figure 
sous les numéros 1 et 2 , de 1820 à 1850 , on prenait annuellement et en moyenne de 1,000 à 1,200 oiseaux; une année on est allé à 1,כ000.

Nous avons vu que dans la tendue dontj'ai donné l'état, et qui existait en 1832, on prenait par jour 8 oiseaux par cent raquettes et lacets.

Au contraire, on n'obtenait,

$\begin{array}{ccccccc}\text { Dans la tendue no } & 1 \text { du tableau, que } 1 & \text { oiseau par } 133 \text { raquettes. } \\ - & 2 & - & 2 & - & 150 \text { id. et lacets. } \\ - & 3 & - & 2 & - & 106 & - \\ - & 4 & - & 4 & - & 108 & - \\ - & 5 & - & 3 & - & 123 & - \\ - & 6 & - & 5 & - & 110 & -\end{array}$

Il n'est donc pas étonnant que les dénicheurs se plaignent de trouver moins de nids qu'autrefois, et que la rareté des oiseaux ait été très-remarquée sur les rives des plaines et surtout par les horticulteurs.

A des tendues dont j'ai eu connaissance, on a pris des coucous dans la première quinzaine d'août, des engoulevents, des gobe-mouches à collier, des traquets tariers, des traquets rubicoles, des pouillots fitis, des fauvettes babillardes, des locustelles tachetées, des torcols, des huppes, des tarins, des linottes, des sizerins, des bouvreuils ponceaux, des pics, des corbeaux-corneilles, des gélinottes. Dans les raquettes de la tendue de M. X., 9 moyens-ducs ont été capturés en un instant.

On a également relevé dans des raqueltes ou dans des lacets, des souris, des belettes, des couleuvres, des grenouilles vertes, des chauves-souris, des putois, des écureuils, des hérissons, des levrauts; ils s'y sont trouvés, il est vrai, en très-petit nombre. 
De la statistique qui précède, il résulte donc déjà :

$1^{\circ} Q u ' i l$ y a en ce moment moins d'oiseaux qu'autrefois ;

$2^{\circ}$ Que l'on prend aux tendues des o iseaux gibiers et des oiseaux sédentaires ;

$3^{\circ}$ Que les petits oiseaux, et surtout les petits insectivores, forment les deux tiers, les trois quarts et même quelquefois les neuf dixièmes des oiseaux capturés.

III.

Avantages de la tendue.

Le but principal de la tendue, et mème le but unique pour quelques 'chasseurs, est la possession de la chair de l'oiseau. Il importe donc d'ètre fixé sur le poids de ces animaux. Ces renseignements sont surtout utiles pour les consommateurs qui les achètent.

Ils paient actuellement de 1 fr. 25 c. à 1 fr. 30 c. la douzaine de rouges-gorges qui, en 1832, se vendait 30,3 à et 40 centimes.

Les chiffres que je vais produire, ainsi que d'autres du même genre qui se trouvent dans cette étude, résultent d'analyses que j'ai faites très-exactement. Cependantje ne les donne pas comme indiscutables, parce que, pour établir un maximum, un minimum et une moyenne relatifs à chaque espèce d'oiseaux de nos pays, il faudrait faire des milliers de pesages. 
POIDS NET D'OISEAUX PLUMÉS, VIDÉS ET DÉSOSSÉS, PRIS DANS LA RÉGION DE SAINT-DIZIER.

\begin{tabular}{|c|c|c|c|}
\hline NOMS DES OISEAUX & $\begin{array}{l}\text { Polds } \\
\text { de la } \\
\text { chair. }\end{array}$ & NOMS DES OISEAUX & $\begin{array}{l}\text { PoIds } \\
\text { de la } \\
\text { chair. }\end{array}$ \\
\hline & $\mathrm{gr}$. & & gr. \\
\hline Engoulevent.......... & 3585 & Torcol............... & 2640 \\
\hline Gobe-mouches gris..... & 750 & Pic-épeichette......... & 10 \\
\hline Gobe-mouches à collier. & 580 & Pic-épeiche.......... & 36 \\
\hline Gobe-mouches noir..... & $\begin{array}{ll}6 & 80\end{array}$ & Pic-vert............. & 105 \\
\hline Pipit des arbres........ & 1165 & Huppe.............. & 41 \\
\hline Traquet tarier........ & 815 & Coucou.............. & 71 \\
\hline Traquet rubicole....... & 735 & Merle noir........... & 56 \\
\hline Troglodyte d'Europe.... & 4 & Grive chanteuse ... & 3960 \\
\hline Roitelet huppé ....... & 262 & Grive mauvis......... & 4170 \\
\hline Roitelet triple bandeau.. & 2 & Grive draine ......... & 6920 \\
\hline Mésange charbonnière... & 775 & Grive litorne......... & 6850 \\
\hline Mésange noire......... & 370 & Moineau friquet........ & 1280 \\
\hline Nésange bleue......... & 375 & Bruant jaune......... & 13 \\
\hline Mésange nonnet & 455 & ordinaire....... & 1160 \\
\hline à longue queue & 385 & Pinson d'Ardennes ..... & 896 \\
\hline Pouillot fitis........... & 450 & Chardonneret......... & 650 \\
\hline Pouillot véloce......... & 4 & 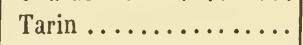 & 750 \\
\hline Pouillot siffleur........ & 410 & Linotte vulgaire ....... & 8 \\
\hline Accenteur mouchet.... & 1075 & Sizerin cabaret........ & 480 \\
\hline Fauvette à tête noire... & 710 & Verdier............. & 15 \\
\hline Fauvette des jardins.... & 1260 & Bouvreuil vulgaire ...... & 1040 \\
\hline Fauvette babillarde..... & 580 & Bouvreuil ponceau..... & 965 \\
\hline Fauvette grisette...... & 770 & Gros-bec.................... & 3565 \\
\hline Hippolaïs ictérine...... & 925 & Martin-pêcheur....... & 2012 \\
\hline Hippolaïs polyglotte.... & 530 & Pie-grièche grise....... & 3360 \\
\hline Rousserolle-effervatte... & כ 40 & Pie-grièche écorcheur... & 1510 \\
\hline Locustelle tachetée..... & 670 & Geai ............... & .80 \\
\hline Rouge-gorge ......... & 730 & Pie ................ & 140 \\
\hline Gorge-bleue.......... & 1363 & Corbeau-corneille ...... & 220 \\
\hline Rouge-queue tithys..... & 890 & Grand-ramier.......... & 257 \\
\hline Rossignol de muraille... & 9 & Tourterelle........... & $11 \partial$ \\
\hline Rossignol........... & 1140 & Perdrix grise......... & 21980 \\
\hline Grimpereau........... & 340 & Faucon cresserelle ..... & 171 \\
\hline Sittelle torchepot....... & 1150 & Buse vulgaire......... & 663 \\
\hline
\end{tabular}


Tel est le poids de la chair d'oiseaux qu'à ma connaissance on a pris en plus ou moins grand nombre aux tendues.

Pour les amateurs qui ne vident pas les petits oiseaux, le poids est un peu moins insignifiant, mais il n'est jamais assez considérable pour justifier ce genre de chasse exceptionnelle.

Il faut, d'ailleurs, pour compter juste, déduire de la valeur brute de la viande tous les frais de construction et d'entretien de la tendue, de la préparation des oiseaux.

Par exemple, on ne fait que 100 raquettes en coudrier par jour, on n'en fabrique que 50 avec ressort en fil de fer.

Pour plumer et vider une douzaine d'oiseaux, il faut au moins une heure.

Les chiffres que j'ai livrés à l'attention du lecteur restent donc avec toute leur éloquence.

Les défenseurs de ce genre de chasse font valoir que les tendues sont l'occasion de promenades agréables et surtout excellentes pour la santé, qu'elles développent et entretiennent, surtout chez les enfants, l'énergie, la vigilance, l'adresse, les goûts militaires. Comme nous le verrons plus loin, ces allégations ne sont pas sans réplique. 
IV.

Conséquences malheureuses de la tendue.

$1^{\circ}$ AU POINT DE VUE DES OISEAUX SÉdeNTAIRES.

Le poids de la chair des petits oiseaux étant si peu considérable, on voit qu'une tendue n'est avantageuse qu'à la condition d'en détruire beaucoup.

Or, s'ils nous sont nécessaires comme travailleurs ou comme artistes, si la destruction que l'on en fait est excessive, au point de nous priver d'avantages incomparablement plus grands que celui de leur chair, il est évidemment de l'intérêt général de supprimer ce genre de chasse.

L'observation démontre que la plupart des oiseaux pris dans les tendues des bois sont nécessaires à la conservation et au développement de la richesse publique, et que nous trouvons beaucoup d'autres avantages à les laisser vivre.

La loi l'a reconnu pour les oiseaux sédentaires, et cependant ce sont eux qu'on prend les premiers aux tendues. Quand cette chasse commence, les oiseaux qui ont vécu paisiblement dans leur résidence habituelle vont, sans défiance, se percher sur les raquettes aussitôt qu'elles sont installées.

On y détruit aussi bien et mieux encore les oiseaux de jardins.

Pour la plupart de nos oiseaux sédentaires, l'heure du départ arrive également bientôt; alors ils se mettent en marche pour le Midi; ils deviennent ainsi des 
oiseaux de passage et cessent de jouir de la protection de la loi. Il leur suffit quelquefois de changer de territoire pour franchir la limite d'un département.

Au 29 septembre 1871, j'avais encore dans mon jardin des fauvettes à tête noire qui, grâce à ma protection, avaient pu travailler et orner ma demeure depuis le 31 mars, jour de leur arrivée.

Aussitôt leur départ, ces chers oiseaux ayant quelques raisons de croire que tous les perchoirs des bois et bosquets sont aussi inoffensifs que ceux de mon jardin, auront été tête baissée se jeter dans un piége.

De même, et c'est là un fait très-curieux au point de vue scientifique, au moyen d'un nid artificiel, en 1869, j'ai attiré dans mon jardin deux mésanges bleues. Elles ont, chaque année, fait deux couvées et n'ont pas émigré. En hiver, pendant les grandes gelées de 1870 et 1871, elles venaient plusieurs fois par semaine visiter leur nid. Assurément, pendant leurs excursions, elles auraient pu être prises aıx raquettes.

Ne conviendrait-il pas que les chasseurs des pays voisins, et surtout ceux du Midi, permissent aux ouvriers ailés que j'ai, en quelque sorte, élevés, de venir reprendre leur tâche au printemps? Il est bon qu'on sache, en effet, que l'oiseau revient s'établir là où il a déjà niché, si rien d'extraordinaire ne s'y est passé, si la maison de l'hirondelle n'est pas brûlee, si le bois n'est pas défriché, l'étang desséché, le champ planté, si, en un mot, les conditions de vie ne sont pas radicalement changées. 
$2^{\circ}$ au point de vue de l'oiseau de passage.

D'après la loi, il semblerait que l'oiseau de passage ne rend pas de services : c'est une très-grave erreur.

D'abord, aussitôt l'élevage terminé, les petits s'éloignent de la résidence maternelle et vont jusqu'au moment des migrations explorer le voisinage.

Les travaux qu'ils accomplissent sont complétés par les oiseaux de passage.

Ces derniers sont, en effet, dans ces cas-là, des régulateurs de l'élimination.

Ce qui prouve qu'ils rendent de grands services, c'est que, bien qu'ils soient très-nombreux, ils sont extrêmement gras.

Ils arrivent en automne, non-seulement pour éliminer ce qu'il y a de surabondant parmi les végétaux et les animaux, mais surtout pour tempérer l'action des agents chargés de la décomposition des corps.

Or, ne serait-il pas juste que les propriétés que doit traverser l'oiseau quittant dans le Nord son domicile d'été, pour aller pendant l'hiver stationner et résider dans le Midi, profitassent également des travaux des oiseaux de passage, par analogie de ce que, conformément à l'article 644 du code civil, celui dont l'héritage est traversé par une eau courante peut en user, mais à la condition de la rendre à la sortie de ses fonds à son cours ordinaire?

Enfin, même relativement aux pays dans lesquels 
nos oiseaux de passage sont sédentaires, nous ne sommes pas aussi désintéressés qu'on pourrait le croire.

Il existe une certaine solidarité d'intérêt entre tous les habitants d'une même région du continent, solidarite que les divisions de territoire et de propriété laissent subsister. Quand les bois du Nord manquent, nous Jes payons plus cher. Quand le Midi de la France et l'Afrique n'ont pas des produits abondants, nous en ressentons le contrecoup.

De plus, les insectes qui se sont multipliés d'une manière anormale dans une contrée, émigrent souvent dans une autre. Ces émigrations ne se portent pas en un jour à de grandes distances, mais par leur marche progressive elles finissent par s'étendre d'une commune à une autre, de canton à canton, de département à département.

C'est ainsi que le coccus, insecte mycroscopique, finit par envahir la plupart des arbres du Midi de la France.

Pour qu'on puisse juger de l'importance des oiseaux de passage dans les bois, je produis des états que j'ai dressés en 1872 et 1873 d'après mes observations pour la région de Saint-Uizier. 


\begin{tabular}{|c|c|c|c|c|}
\hline NOMS DES OISEAUX & $\begin{array}{c}\text { ARRIVÉE } \\
\text { du premier }\end{array}$ & $\begin{array}{l}\text { FIN DU } \\
\text { passage }\end{array}$ & $\begin{array}{l}\text { COMMENCEMENT } \\
\text { du passage }\end{array}$ & $\begin{array}{c}\text { DÉPART } \\
\text { du dernier }\end{array}$ \\
\hline 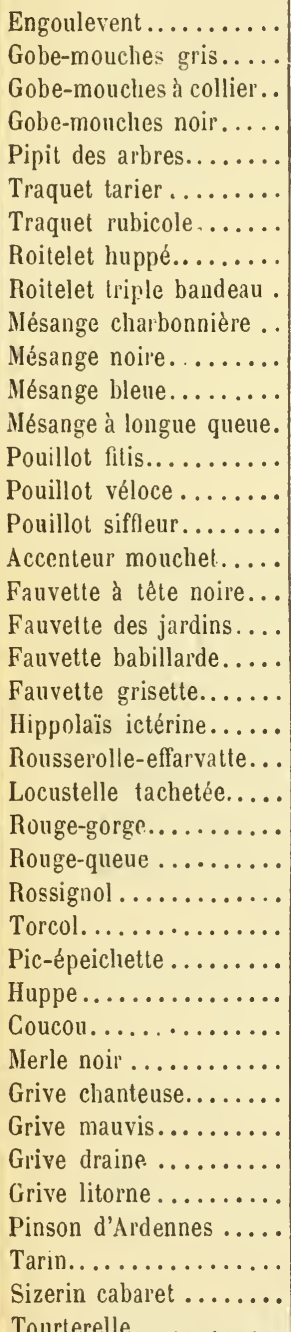 & $\begin{array}{l}20 \text { mars } \\
18 \text { mars } \\
19 \text { mars } \\
31 \text { mars } \\
15 \text { avril } \\
19 \text { avril } \\
11 \text { avril } \\
26 \text { avril } \\
16 \text { avril } \\
20 \text { avril } \\
12 \text { avril } \\
14 \text { avril } \\
2 \text { avril } \\
3 \text { avril }\end{array}$ & $\begin{array}{l}20 \text { avril } \\
1 \text { er avril } \\
1 \text { er mars } \\
1 \text { er mars }\end{array}$ & \begin{tabular}{|c|}
9 octobre \\
1 or octobre \\
Septembre et octobre \\
Aoùt et septembre \\
Septembre et octobre \\
Septembre et octobre, les \\
blanches vers le 25 oct. \\
30 septembre \\
En septembre \\
2 octobre
\end{tabular} & $\begin{array}{l}15 \text { septembre } \\
15 \text { septembre } \\
15 \text { aoùt } \\
1 \text { er décembre } \\
25 \text { novembre } \\
4 \text { octobre }\end{array}$ \\
\hline
\end{tabular}


En examinant ce tableau, on peut voir que certaines espèces d'oiseaux de passage nous fournissent plus de journées de travail que quelques espèces de nos oiseaux sédentaires, que le plus souvent elles nous en donnent un grand nombre, tandis que nos oiseaux sédentaires travaillent souvent très-longtemps au dehors de notre région.

$3^{\circ}$ DOMMAGES OCGASIONNÉS DANS LES FORÊTS, PRẺS DES habitations, SUR LES RIVES DES EAUX ET DANS LES plaines, Par la destruction des oIseaux des Bols.

Quand les oiseaux sédentaires et de passage ne sont pas assez nombreux pour compléter leur tâche, il en résulte des dommages très-grands dans les bois. Cela ne frappe pas les yeux et l'esprit de tous, parce que ces dommages se produisent à longue échéance; ainsi, souvent un beau chêne devient sans valeur, parce que, ๖ั 10, 20, 30 ans avant, il a été attaqué par les insectes sans qu'on ait pu s'en apercevoir.

La diminution excessive des oiseaux, qui a été remarquée dans ces derniers temps, pourra bien être pour un avenir prochain une cause de désastres sur lesquels nous n'aurons plus alors qu'à gẻmir.

Actuellement déjà, il se produit dans les forêts des dommages que chacun peut constater, et beaucoup d'entre eux ont eu pour cause au moins partielle l'insuffisance des oiseaux. Tels sont les places dénudées, le bois mort, des variétés de chablis, les 
chênes sans feuilles, dépérissant, découronnés ou rongés au pied.

Depuis une vingtaine d'années, nous n'avons plus que de loin en loin les glands et les faînes en abondance.

La destruction excessive des oiseaux serviteurs des bois a des conséquences bien autrement étendues. Ce sont les bois qui fournissent le plus grand nombre des oiseaux nécessaires aux habitations, aux jardins, aux rives des eaux et même à la plaine, et à ce titre ces sylvains se trouvent être d'une utilité générale, car ils fournissent un contingent annuel et très-considérable, qui va nicher dans ces divers lieux.

De plus, et surtout au moment des grandes migrations, nous voyons apparaître dans les petits bois, dans les jardins, les mésanges, les pinsons, les fauvettes, les roitelets, surtout quand leurs congénères n'ont pu y nicher; dans les vignes, après les vendanges, les pies, les tourterelles; dans la plaine, après les moissonneurs, les tourterelles, les linottes, les moineaux domestiques, les chardonnerets, les étourneaux, les corbeaux.

Aussi il est à remarquer que les espèces d'oiseaux proprement dits de plaine ne sont pas nombreuses, et qu'elles se complètent par le contingent d'oiseaux qui leur vient des bois.

Supposons que les forêts de France soient défrichées, ou, ce qui revient au même, que le nombre des sylvains ait subi une très-notable diminution, il en résulterait des conséquences malheureuses, même en dehors des forêts, notamment sur les arbres fruitiers. 
Il est à remarquer que les comices agricoles, dans ces derniers temps, n'ont pas cessé de se plaindre de l'envahissement des insectes et des désastres dont ils sont la cause.

L'utilité des sylvains par rapport à la plaine se démontre encore autrement. Dans tous les bois, il y a des herbages dont vivent les insectes de la plaine et qui les attirent.

Les insectes ailés des bois font souvent des excursions dans les champs, les insectes des champs viennent très-souvent confier leurs œufs aux lisières des forêts, aux bosquets, aux arbres, aux haies. Ces œufs y trouvent à la fois un abri et, aux premiers rayons du soleil, une chaleur concentrée, et ils sont moins exposés que ceux qui sont déposés dans la plaine si souvent parcourue par le laboureur et son bétail. Il en résulte que beaucoup de sylvains n'ont pas de déplacement à faire pour les détruire. De plus, les oiseaux de passage aiment à stationner aux lisières des forêts et dans les bosquets pour réparer leurs forces et se préparer à de nouvelles fatigues. C'est là surtout que les tendues sont établies; c'est logique pour les chasseurs, mais peu consolant pour l'agriculteur.

$4^{\circ}$ PROPORTION DES PERTES OCGASIONNÉES PAR LA DESTRUCTION DES PETITS INSECTIVORES. IMPOSSIBILITÉ D'Y IREMEDIER.

C'est bien à tort que les tendeurs disent que les travaux des oiseaux sont insignifiants. L'oiseau serviteur a, dans le mouvement des forces de la production, le rôle que remplissent le frein et l'ai- 
guillon par rapport à l'animal de trait, le compensateur, le régulateur dans les machines; pourquoi prétendre être plus sage que Dieu et vouloir faire d'un frein un moteur principal ?

D'ailleurs, en observant, on voit que l'oiseau est un frein et un aiguillon, un régulateur d'une puissance relativement très-grande, et cela est vrai, surtout des sylvains et des petits oiseaux qu'on prend dans les tendues.

De la coïncidence remarquée entre la diminution des oiseaux et l'augmentation des insectes, on a conclu qu'en cela il y avait une relation de cause à effet.

De la spécialité des diverses espèces d'éliminateurs, et surtout de la spécialité si remarquable des oiseaux, on a conclu facilement aussi que le vide produit par leur absence ne pouvait être comblé, et que la destruction de ce moteur ailé amenait fatalement de graves perturbations dans le mouvement des forces végétales.

En ce qui concerne les sylvains, et surtout les plus petits d'entre eux, ajoutons quelques faits et observations qui démontreront suffisamment que le rôle de ces oiseaux est loin d'ètre insignifiant, que même il est très-considérable, et qu'en raison de leurs aptitudes particulières ils ne peuvent être remplacés.

Les petits insectivores ont pour mission surtout de rechercher les petits insectes, leurs œufs, et aussi les œufs des plus gros, qui en très-grand nombre sont disséminés et cachés sur les branches touffues des buissons et sur les écorces des arbres, dans les herbages qui couvrent la surface du sol, par consé- 
quent dans les lieux d'un accès difficile, sourent très-sombres, surtout au moment principal des repas, le matin et le soir.

J'ai pu calculer qu'une mésange bleue avait fait en une journée d'été 23 kilom. ; chacun a pu constater, en effet, que cet oiseau et beaucoup d'autres de la même taille sont sans cesse en mouvement. C'est à peine si le roitelet laisse au chasseur le temps de le viser; aussi n'est-il pas étonnant que les auteurs aient donné à ces petits oiseaux le nom générique de passereaux (1).

Les déplacements si multipliés des petits passereaux sont nécessaires, parce que ces petits oiseaux, chargés de l'elimination des infiniment petits, ont besoin, pour se mettre à la recherche de leur proie, de passer sans cesse d'un observatoire à l'autre. Leurs yeux ontla pénétration du microscope ; mais pour découvrir dans les herbages, dans les mousses, dans les crevasses du bois et de la terre, un oruf de mouche ou de puceron, il leur faut les braquer constamment et dans toutes les directions. Les petits passereaux peuvent d'ailleurs se transportersur le roseau ou l'arbuste des marais sans nacelle, traverser une rivière sans pont, monter sur un arbre sans échelle, gagner l'extrémité des plus petites branches sans échafauds, traverser un massif sans tunnel, aller très-vite sans chemin de fer, pratiquer toutes les éliminations nécessaires sans l'outillage

(1) D'après mon savant ami II. Vincelot (Les noms des oiseaux expliqués par leurs mœurs, p. 132), le mot passereau, comme le latin passerulus (Pline), est le diminutif de passer, passeris, il a la même racine que passus (pas), d'où est venu le verbe de la basse latinité, passare (passer), signifiant aller d'un endroit a un autre sans s'y tixer longtemps. 
si varie, si complinué de l'industrie humaine, c'està-dire, se transporter toujours et très-vite là où l'élimination a besoin d'un complément de forces, inspecter en une journée un ou plusieurs territoires.

Comment le tendeur pourra-t-il remplacer un agent si spécialement, si merveilleusement organisé ?

Malgréla difficulté du métier, les petits passereaux trouventmoyen de faire des insectes une destruction bien étonnante.

D'après Gloger (De la nécessité de protéger les animaux utiles, p. 43, 44), la mésange bleue ne létruit pas moins de 200,000 insectes en une année.

Celte appréciation ne semble pas exagérée, car 20,000 œufs de papillon de grandeur moyenne ne pèsent que 16 grammes, et 20,000 œufs de puceron n'en pèsent pas moitié. En hiver, il n'est pas rare que les œufs d'insectes figurent pour le sixième, le quart et même le tiers dans un repas de mésange, et cet oiseau a besoin chaque jour pour le moins de 8 grammes de nourriture. M. de la Blanchère (Les Oiseaux utiles et les Oiseaux nuisibles, p. 83) dit même que la mésange bleue mange par jour, d'après sa conduite en captivitè, 15 grammes d'œufs de papillon.

En ouvrant des estomacs de mésanges, j'ai cru reconnaître que ces chiffres donnés par des auteurs se rapprochaient beaucoup de la vérité. J'ai établi moi-mème que deux de ces mésanges, en nourrissant 10 petits, avaient détruit en une journée de 1,000 à 1,200 insectes, dont 400 chenilles. Le 18 mai 1870 , à quatre heures du matin, je me suis installé 
près d'un nid de cet oiseau, et j'y suis resté jusqu'à 8 heures du soir; de 4 h. $30 \mathrm{~m}$. du matin jusqu'à $7 \mathrm{~h} .8 \mathrm{~m}$. du soir, les père et mère ont fait 459 voyages. En moyenne chaque voyage, aller et retour, était de 100 mètres, ce qui donne un total de 43,900 mètres pour tous les voyages de la jour. née.

C'est en tenant compte de ce que j'ai vu ce jourlà et de ce que j'ai constaté en d'autres circonstances, que j'ai pu établir ce total de 1,000 à 1,200 insectes.

ll est donc très-vraisemblable que la mésange bleue détruit annuellement plus de 200,000 des rongeurs du règne végétal. Pour se faire une idée exacte des services qu'elle rend à l'agriculture, il faut tenir compte de l'innombrable progéniture qui était assurée à ces 200,000 insectes, et des ravages dont les hommes auraient eu à souffrir.

M. Morren a calculé qu'un seul couple de pucerons du printemps était la souche annuelle d'un quintillon d'individus (Dictionnaire universel d'histoire naturelle, au mot puceron, par Charles d'Orbigny).

Il importe aussi de remarquer que la mésange bleue fait chaque année 2 pontes, la première de 10 œufs, du 6 au 11 mai ; la seconde de 8, du 19 mai au 15 juin, sauf quelques variations.

Cette reproduction si remarquable s'explique non-seulement par l'immense fécondité des insectes que cet oiseau détruit, mais encore parce que lui-même est soumis à de nombreuses chances de destruction soit pendant la periode des nids, soit pendant le reste de l'année. 
Ces chiffres ne démontrent-ils pas surabondamment combien cette mésange est un rouage essentiel dans le mécanisme de l'élimination?

La sittelle mange deux fois plus que la mésange bleue.

Les rouges-gorges et les rouges-queues, que nous voyons sans cesse en observation et en chasse, c'est-à-dire en mouvement dans les buissons et dans les herbages, font également une très-importante consommation des insectes, de leur's œufs et de leurs larves. C'est en effet sur le sol et à proximité du sol que le plus grand nombre des insectes réside et opère ses éliminations, parce que là sont déposés les graines, et que la surface du sol est complétement occupée par les racines des plantes et des arbres.

C'est là que le chêne est attaqué, quand il sort du gland pour devenir un baliveau, puis une futaie.

Assurément les tendeurs n'ont jamais eu à leur disposition ces renseignements et d'autres du même genre ; ils n'ont jamais su que, pour manger $3^{\text {gr }} 70^{\mathrm{c}}$ de mésange bleue, $7^{\mathrm{gr}} 30^{\circ}$ de rouge-gorge, ils pouvaient causer d'aussi graves préjudices aux plantes et aux arbres si nécessaires cependant à la vie humaine.

Je les prie de s'inspirer de ces chiffres et de calculer combien de mal on a pu faire au moyen des tendues dont j'ai donné plus haut la statistique.

On a pris en 1871 et 1872, dans 6 tendues, 3,239 insectivores, qui n'ont produit que le poids insignifiant et dérisoire de $22^{\mathrm{k}} 743^{\mathrm{gr}} 8 \mathrm{o}^{\mathrm{c}}$ de viande, et on a ainsi détruit 3,239 machines appelées à rendre notre vie matérielle moins difficile et moins coù- 
teuse, et notre vie spirituelle et morale beaucoup plus agréable.

$\check{\jmath}^{0}$ RÉPONSES A QUELQUES OBJECTIONS.

Apres cet exposé, il semble inutile de faire une plus longue critique des tendues, cependant il importe de ramener les tendeurs et les dénicheurs, sinon à l'admiration, du moins au respect de l'oiseau et surtout des petits insectivores.

Ajoutons donc quelques mots de réponse aux objections qu'on a produites.

On dit : il y a moins d'oiseaux qu'autrefois, mais cela ne vient pas des tendues. - Cependant, on ne trouve de l'intérêt à tendre que lorsqu'on prend beaucoup d'oiseaux; on n'en épargne aucun de ceux qu'on peut atteindre, on donne aux dénicheurs l'exemple d'une destruction qui n'est pas rationnelle. On détruit et on fait ainsi détruire un grand nombre d'oiseaux utiles. Il faut d'autant moins agir de la sorte, qu'il existe d'autres causes de destruction moins connues et pour lesquelles il n'y a point de remèdes.

Un tendeur dira au contraire: Je ne remarque pas que je prenne moins d'oiseaux que par le passé. Cela pourrait être, sans qu'on puisse en conclure qu'il y en a autant qu'autrefois; comme les hommes, les oiseaux ont des voies qu'ils fréquentent plus que d'autres.

Un tendeur intelligent s'est naturellement installé là où on a toujours remarqué des passages abondants. Il peut y être très-favorisć, quoiqu'il y ait ailleurs pénurie d'oiseaux. 
Le propriétaire qui détruit beaucoup d'oiseaux dans son bois, soit en les prenant à la tendue, soit en tolérant le dénichage, peut même n'être pas immédiatement victime de cette destruction, parce qu'en général, si l'oiseau niche où il a niché, et si lors des grandes migrations il passe dans les contrées qu'il a déjà visitées, il va aussi nicher et il opère ses passages dans les lieux où il trouve les insectes très-abondants, et par suite la vie plus facile. Cette répartition des oiseanx sur tous les points de la terre au fur et à mesure des nécessités de l'élimination fait que, quand ils ne sont plus assez nombreux, le propriétaire qui a le plus contribué à leur destruction n'est pas puni dans la proportion de sa faute. Et n'est-ce pas là une raison, pour que ceux qui ne tendent pas demandent la suppression des tendues?

A ceux qui objectent que les tendues produisent au département de la Meuse une valeur de plusieurs millions, il faut répondre qu'ils se trompent. Si on faisait la statistique de toutes les tendues de la Meuse, on trouverait un total de grammes de viande insignifiant en comparaison des produits de la boucherie de cette région, et on constaterait, par la même occasion, que ce département, en détruisant par centaines de mille d'utiles éliminateurs, produit un certain renchérissement de denrées de toute sorte dans la Meuse et même dans des pays très-éloignés de ce département.

Aux tendues, dit-on, on prend des geais et autres animaux nuisibles. C'est déjà reconnaître implicitement que les autres oiseaux ne sont pas nuisibles. Pour être édifié à ce sujet, que l'on consulte les 
tableaux de la page 19. J'ai dans mes cartons d'autres tableaux du même genre et qui les confirment.

Oui, on prend aux tendues des geais et quelques oiseaux de proie, précisément parce que ces oiseaux sont attirés, comme les braconniers, par l'appas d'un oiseau facile à prendre, mais ils sont en petit nombre, et en une pipée au fusil on détruirai autant de geais qu'on en prend pendant une saison à la tendue.

$6^{\circ}$ DES EFFets DE LA TENDUE AU POINT DE VUE MORAL.

Pour justifier les tendues, on a dit que cette chasse était un moyen de développer les forces, la vigilance, l'énergie des enfants, et qu'elle était une excellente préparation à la vie militaire.

Dans ces assertions il y a du vrai, mais en cela comme toujours, il faut dire toute la vérité.

Il existe beaucoup d'autres moyens de favoriser le développement des forces physiques et morales de l'enfance et de l'adolescence.

Les tendeurs ne sont pas assurément ceux qui ont fourni le plus de héros et de grands capitaines.

Au contraire, la tendue développe facilement de mauvais instincts ; n'est-ce pas prendre le contrepied de la genérosité el s'aventurer dans les voies d'une indifférence coupable et mème de la cruauté, que de s'habituer à voir soufirrir de charmants petits êtres et nême à causer leurs souffrances? Lo tendeur qui a pris 1,000 oiseaux, leur a fait subir les supplices de l'agonic pendant plusieurs milliers 
d'heures avant de leur tordre le cou ou de leur écraser le cœur, ce qui est très-contraire à l'esprit de la loi dite de Grammont.

Il ne faut pas oublier non plus que l'enseignement le plus universel et le plus pénétrant est celui de l'exemple.

Or, quel est l'enseignement principal que donne le tendeur? Voici ce que d'une manière pratique il dit:

Tous les oiseaux, même les plus jolis, les meilleurs chanteurs, ceux qui rendent d'immenses services par leurs travaux, sont surtout créés pour servir de nourriture. Donc la tendue, malgré ses répugnances pour les âmes trop sensibles, ne peut ìtre illicite pour qui l'exerce sur sa propriété.

Il est à remarquer que la tendue prend sans pitié tous les oiseaux.

Cette théorie est d'une morale trop facile pour ne pas être acclamée par tous ceux qui, pour une raison quelconque, se sentent portés à capturer les oiseaux. Leur conscience est allégée par l'exemple de ceux qui, par la richesse de leurs propriétés forestières, la renommée de leur chasse, jouissent d'une certaine considération; il n'y a plus qu'une question de garde ou de gendarme. Pas vu, pas pris, cette formule vulgaire devient la limite du droit, et il arrive que l'enfant de l'ouvrier va dénicher les jeunes oiseaux et même prendre les mères au piége pendant l'incubation. Plus tard il fait des tendues volantes, il glisse dans le braconnage, l'allié naturel du vice et du crime. La tendue est donc très-proche parente du dénichage, souvent sa mère; c'est une occasion grave d'infractions continuelles a! droit naturel et au droit positif. 
Ces faits sont très-connus de ceux qui habitent des pays de bois; or, les propriétaires de ces bois ne sont-ils pas intéressés plus que d'autres à ne les autoriser d'aucune façon? N'est-il pas juste qu'ils donnent l'exemple du respect des oiseaux serviteurs, s'ils veulent que le pauvie les respecte? C'est au respect traditionnel de l'hirondelle que nous devons l'élimination si profitable et si prodigieuse des insectes ailés.

$7^{\circ}$ LES OISEAUX Nous CONVIENT AUX ENSEIGNeMENTS ET AUX NOBlES JOIES QUE L'ON TROUVE DANS LA CONTEMPLATION DU BEAU.

Je l'ai guère parlé de l'oiseau qu'au point de vue matériel. Je serais incomplet, assurément, si je ne m'etendais davantage sur son importance morale. Qu'on me permette donc de reproduire à ce sujet quelques pages d'un livre que j'ai publié en 1872.

Dieu merci, nous ne vivons pas seulement de pain et des autres productions de la terre, de tout ce qui se cote à la Bourse et au marché.

La vie matérielle n'est qu'un moyen pour notre vie intellectuelle, et nous avons une soif insatiable du beau, du vrai et du bien. Rien ne nous arrête quand il s'agit de chercher les joies de l'esprit et du cœur: les beaux-arts ont toujours tenu une grande place chez les peuples civilisés ; mais est-il rien de comparable au beau de la nature ? Les chefsd'œuvre des artistes sont aux sublimités de l'univers ce que l'homme est à son Créateur.

Comment, eu entrevoyant quelques-unes de ces 
harmonies du monde des oiseaux, ne pas se sentir profondément ému et saisi d'admiration et d'amour?

N'est-ce pas merveilleux que, sous les apparences de la liberté ou même du caprice, les oiseaux forment les rouages d'une immense et bienfaisante machine qui englobe notre monde, que certains de ces rouages fonctionnent souvent en quelques jours sur un espace de plusieurs centaines de lieues, avec une régularité et une grâce parfaites, selon les desseins du Créateur? Malgré ses nombreuses et élégantes évolutions, l'hirondelle va, en huit jours, d'Angleterre en Guinée !

Dans l'exposéqui précède, combien de foisn'avonsnous pas eu l'occasion d'admirer le rôle si remarquable de l'oiseau dans les grandes harmonies de l'élimination? A d'autres points de vue, il n'est pas moins digne d'attention.

Il est un chef-d'œuvre de mécanique, la plus adinirable des machines agricoles, le modele des machines de locomotion aquatique et probablement aérienne.

Aussi les palmipèdes ont donné l'idée de la rame, les nageurs et les plongeurs ont servi de modèle pour la construction et la décoration des navires.

Les formes des oiseaux sont toujours complétement en rapport avec leur spécialité de travailleurs, ct elles ont toutes la beauté et la grâce que comportent ces formes.

Les harmonies organiques ne sont pas moins remarquables dans les détails que dans l'ensemble. nn peut en juger par la beauté d'une plume. 
Les couleurs des yeux, du bec, des pieds et surtout des plumes sont si merveilleusement combinées, qu'elles caractérisent distinctement et embellissent chacune des milliers d'espèces connues, d'après son sexe, son âge et les saisons.

Les plumages gris qui ont été départis au plus grand nombre dans nos pays tempérés, ont euxmêmes reçu des nuances et des variétés de dessins qui leur donnent un cachet particulier. Il est d'ailleurs beaucoup d'oiseaux, surtout dans les pays chauds, qui, comme les papillons et les minéraux, ont èté dotés des plus riches couleurs, et ils ont souvent fourni des parures aux femmes et aux guerriers.

Beaucoup d'entre les oiseaux sont de véritables musiciens. Toujours et partout, ils prodiguent leurs concerts : ils les donnent à ceux qui sont déshérités des joies du monde etdes délicatesses de la musique du Conservatoire.

Les oiseaux de nos contrées possèdent dans leur voix plus de timbres diver's que les plus grands orchestres.

Ils se jouent des commas de notre gamme, et, dans la libre carrière qu'ils parcourent, ils trouvent des hardiesses originales qui ne produisent jamais rien de discordant pour l'harmonie; ils abordent une bonne partic de notre échelle des sons, et ils ont ainsi à leur façon des ténors, des barytons, des basses.

La plupart font, dans les ensembles, des paries d'accompagnement; ils composent un fonds d'harmonie qui s'enrichit constamment de solos donnés 
par l'alouette, le pouillot, l'hippolaïs, la fauvette, le rouge-gorge, le troglodyte et surtout le rossignol. Tous leurs accents sont empreints d'entrain et de gaieté.

Il en résulte des psalmodies pleines de vie et de clialeur, une harmonie variée, de délicates et bruyantes ariettes.

Cette musique est si expressive qu'on lui a donné le nom de chant.

Or, les chants des oiseaux ne sont-ils pas des actes de reconnaissance et d'espérance, et, pour les hommes, une invitation à la prière?

Ce qu'il y a de certain, c'est qu'ils n'éveillent aucune mauvaise idée, aucun mauvais sentiment, et qu'ils sont l'expression des joies pures que nous trouvons dans toutes les harmonies de la nature.

Le chant des oiseaux est un Te Deum qui s'élève de tous les points de la campagne et des bois.

La beauté qui, sous tant de formes, leur a été prodiguée, sera toujours pourles poëtes une inépuisable mine.

Quels attraits n'ont pas la tendre sollicitude de la couveuse, de la mère pour ses petits, les touchantes unions de presque toutes nos espèces, les affectueuses démonstrations de l'oiseau apprivoisé, la majesté de l'aigle, la noble gravité du duc, la magnificence du paon, l'aimable pétulance des passereaux, la grâce de la fauvette, l'élégance de la bergeronnette, le vol ondulé de l'hirondelle, la cour'se légère et rapide du chevalier, l'imposante navigation du cigne, les nuances variées des plumages, surtout sous les livrées du prin- 
temps, le blanc lustré du grebe, les éclatantes couleurs du chardonneret, le plastron pourpré du bouvreuil, le manteau vert dı martin-pêcheur, la robe dorée du loriot, la couronne du roitelet, l'hymne de l'alouette, le chantécla tant du scrin, du chardonneret et de la linote, l'air brillant de la grive, les sons de voix filés et les douces mćlodies de la fauvette, le chant si varié, si harmonieux et si étendu du rossignol, l'intéressante construction des nids, la légèreté et la grâce de ces berceaux, le riche coloris de l'œuf?

A combien d'agréables rêveries n'ont pas donné lieu tous ces joyaux des parures de la nature? Partout et toujours elles ont surexcité l'imagination des poëtes et des peuples. Il cn est résulté pour l'histoire naturelle une surcharge de contes les plus fantastiques. De là l'invention du phénix, qui renaissait de ses cendres; de la harpie, qui avait une belle tête de femme et un corps d'oiseau de proie, etc.

La science héraldique a aussi trouvé que les oiseaux, malgré leurs variétés, ne suffisaient pas aux nécessités de son langage et de ses insignes symboliques; elle les a modifiés et même defigurés, de telle sorte qu'il faut les étudier souvent plus dans l'histoire du blason que dans l'histoire naturelle.

Assurément donc, l'oiseau est bien admirable, et cependant il n'a que l'ombre de la liberté; il est comme un simple, mais magnifique instrument entre les mains de Dieu.

Le rossignol chante toujours le même air; toujours les chardonnerets ont fait le même nid; les migra- 
lions doubles et périodiques de chaque année n'ont pas varié d'une manière sensible.

l'élude del'oiseau nous mène donc directement à Dieu, et son vol rapide dans les hautes régions de l'air attire notre regard et nos pensées vers le ciel. Cet être si admirable est tout à la fois un artiste et un professeur; si Dieu n'avait pas voulu qu'il en fît ainsi, il aurait pu lui donner le mutisme de l'insecte et la Jaideur de la chauve-souris.

Il a donc été créé pour nous convier auxjoies de l'esprit et du cœur, pour exciter notre foi et nos e pérances, en développant le sentiment du beau, du vrai, du bien. 


\section{CONCLUSION.}

D'abord, et ainsi que nous l'avons dit, un Conseil général ne peut avoir la prétention d'imposer son avis. Le préfet a, malgré cet avis, qui n'est que consultatif, le droit de ne pas autoriser les tendues.

Il appartient surtout au ministre de l'intérieur de consulter les conseils généraux et les autres autorités compétentes d'une région entière et de recommander aux préfets les mesures qui lui paraissent les plus utiles à l'intérêt général.

A notre époque et dans nos régions, il semble évident qu'il n'y a plus assez d'oiseaux et surtout de petits insectivores.

Il est nécessaire d'empêcher, non-seulement de tendre, mais même de prendre, de tuer au fusil, d'exposer en vente, de vendre, d'acheter, de transporter ou de colporter les petits oiseaux insectivores que le préfet désignerait sous le nom d'oiseaux utiles.

En fait, cette dernière défense n'imposerait pas de grandes privations aux chasseurs, car un petit insectivore ne vaut pas un coup de poudre et de plomb. Elle aurait surtout pour résultat d'empêcher les fraudes des tendeurs.

L’Assemblée législative pourrait en cela compléter les pouvoirs du ministre et des préfets.

Il importe aussi que des règlements internationaux viennent sauregarder ces principes. 
A tout prix le dénichage doit ètre défendu et empèché.

Enfin, les lois de répression ne seront efficaces qu'autant que l'enseignement des écoles et des familles démontrera jusqu'à l'évidence l'utilité des oiseaux serviteurs.

FIN DE LA PRE.UIĖHE PARTIE. 

DEUXIEME PAITIE

(Mémoire de 1876)

INTRODUGTION

Depuis quelque temps les questions qui se rattachent à l'utilité des oiseaux ont été souvent mises i l'ordre du jour dans les comices agricoles, dans quelques conseils généraux et dans les assemblées législatives, et il a été reconnu que la société devait intervenir de manière à protéger efficacement le plus grand nombre de leurs espèces.

Le 27 juin 1861, un très-remarquable rapport a été présenté au Sénat par M. Bonjean, depuis l'une des nobles victimes de la Commune.

Il était l'organe de la deuxième commission, chargée d'examiner diverses pétitions demandant l'introduction de mesures sévères pour la conservation des oiseaux qui détruisent les insectes nuisibles à l’agriculture, et le Sénat a prononcé le renvoi de ce rapport au Ministre de l'agriculture, du commerce et des travaux publics.

L'intervention du pouvoir n'ayant pas eu l'efficacité désirable, de nouvelles pétitions ont été envoyées à l'Assemblée nationale. De là un nouveau rapport présenté par M. Ducuing, le 7 février 1874 , 
et un nouveau renvoi aux Ministres de l'agriculture et de l'intérieur.

Pour donner satisfaction à la chambre, M. le Ministre de l'intérieur prit des mesures nouvelles et écrivit la lettre suivante à son collègue des finances, le 10 août 1874 :

“Monsieur le Ministre et cher collègue,

“Des plaintes nombreuses s'étant produites dans beaucoup de départements au sujet de la disparition croissante des petits oiseaux, j'ai invité récemment MM. les Préfets à rechercher, de concert avec les chambres consultatives d'agriculture, les moyens de remédier à un mal, que le rapporteur de la loi du 24 janvier dernier sur la police de la chasse, qualifiait un fait déplorable pour l'agriculture.

“ Il résulte de la plupart des rapports qui me sont parvenus à ce sujet que la disparition des oiseaux doit être attribuée au dénichage des jeunes oiseaux et des œufs, ainsi qu'à la prise ou à la destruction des oiseaux en général, au moyen de piéges de toute sorte, malgré les prohibitions édictées dans les arrêtés émanant des préfets ou des maires; on a constaté, en même temps, que les agents chargés de la police de la chasse, tels que les gendarmes, les gardes forestiers et les gardes champêtres, négligent dans beaucoup de localités (notamment dans les départements du midi, du nord et de l'est), de relever les infractions aux règlements pris en vertu de la loi du 3 mai 1844.

"J'ai déjà recommandé à MM. les Préfets de prescrire un redoublement de surveillance pour arriver 
à mettre un terme au braconnage qui détruit le gibier proprement dit, ainsi qu'aux déprédations commises par les enfants, qui sont également trèsregrettables au point de vue de l'agriculture; mais j'ai pensé qu'en appelant votre attention sur cette question, dont vous apprécierez toute l'importance, vous voudrez bien me donner votre concours en adressant une instruction spéciale à MM. les Conservateurs des arrondissements forestiers, pour qu'à l'avenir les agents placés sous leurs ordres prêtent un concours très-actif pour assurer la répression de toute infraction aux dispositions légales ou réglementaires qui ont pour objet la conservation des oiseaux utiles à l'agriculture.

" Je vous serai obligé de me faire connaître la suite que vous aurez bien voulu donner à la présente communication.

"Agréez, Monsieur le Ministre, etc.

"Le Ministre de l'intérieur, "Signé : général de Chabaud la Tour ».

A la suite de cette lettre, M. le Ministre des finances s'est lui-même adressé à MM. les Conservateurs des forêts et leur a demandé leur concours pour empècher la destruction excessive des oiseaux, ainsi que le constate la lettre suivante en date du ıั septembre 1874 :

"Monsieur le Conservateur,

"Je vous transmets ci-joint copie d'une dépêche que M. le Ministre de l'intérieur a adressée, le 10 août dernier, à $\mathrm{M}$. le ministre des finances au sujet de mesures à prendre dans l'in- 
térêt de la conservation des oiseaux utiles à l'agriculture.

"M. le Hinistre exprime, dans cette dépêclie, le désir de trouver chez les gardes forestiers un concours actif dans la constatation des infractions aux règlements arrètés à cet effet en exécution de la loi du 3 mai 1844.

“L'article 11 de la loi précitée assimile les infractions de l'espèce aux délits de chasse proprement dits; les gardes négligeraient donc, en ne les relevant pas, un des devoirs qui leur sont imposés.

"Je vous invite, en conséquence, à donner les instructions nécessaires aux agents placés sous vos ordres, afin qu'il soit donné satisfaction au désir de M. le Ministre de l'intérieur, et à tenir la main à leur exécution.

"Vous m'informerez, le cas échéant, des difficultés qui se produisent.

"Vous me rendrez compte des résultats obtenus à la fin de chaque année.

"Recevez, Honsieur le Conservateur, l'assurance de mes sentiments de considération et d'attachement.

"Le directeur général des forèts.

"Signé : Faré ".

Après des actes de cette importance, il était naturel de penser que tout allait être mis en ouvre pour empêcher la destruction abusive des oiseaux.

On a donc lieu d'être péniblement étonné que quelques Préfets aient récemment pris des arrètés contraires à l'esprit de ces prescriptions.

Appelé par la nature de mes recherches sur les 
oiseaux à étudier les questions de dénichage et de tendue, j'ai traité la première dans un ouvrage couronné par la Société centrale d'agriculture, ayant pour titre : Architecture des nids; j'ai, sous le titre de Tendues, fait sur la seconde une étude publiée dans les Mémoires de l'Académie de Reims et qui m'a valu un rappel de médaille d'argent de la Société protectrice des animaux de Paris, et de nombreuses approbations d'ornithologistes, de comices agricoles et de sociétés savantes.

Or, dans ce dernier écrit, j'ai démontré que la chasse des tendues était contraire à l'intérêt général et à l'esprit de notre législation.

Depuis, je me suis enquis de savoir quelles ob= jections nouvelles on pouvait faire, et je n'en ai trouvé aucune qui ne puisse être aisément réfutée. Mes convictions demeurent entières. Pour essayer de les faire partager à tous, j'ajoute à ce que j'ai déjà avancé, quelques développements, des faits, et j'apporte des arguments nouveaux; ce complément ayant surtout pour objet la réhabilitation des oiseaux de passage, je donne pour titre aux deux parties de mon étude: Oiseaux de passage et tendues. 

Les tendues détruisent sans profit pour l'alimentation les plus petits oiseaux insectivores. - Dommages qui en résultent.

On désigne, sous le nom de piége, une machine qui sert à prendre les oiseaux par les pattes, et, par extension, on entend toute machine destinée à leur ravir la liberté.

Les animaux ayant, à la différence des plantes que le botaniste saisit facilement, le privilége de se mouvoir, et ne pouvant vivre sans faire des déplacements continuels, les chasseurs ont d'abord cherché à connaître leur mode de locomotion et surtout les lieux où ils sont obligés de se rendre pour boire ou pour manger. Afin de s'en emparer, ils ont ensuite inventé des engins et des modes de chasse très-variés et appropriés à l'organisme et aux habitudes de chaque espèce. On attrape le cormoran, très-habile plongeur, en tendant des filets sous l'eau; les hirondelles également avec des filets, mais que l'on dresse à une certaine hauteur, comme sur les côtes de la Néditerranée, ou à ras de terre, comme dans les prairies de la Gironde; le canard, en plaçant des piéges à la surface de l'eau; le vanneau, avec des filets qui se meuvent sur des terrains humides et marécageux; les perdrix, les alouettes et les bergeronnettes, au moven de collets suspendus par une baguette à la surface de la 
terre; et beaucoup-de passereaux qui perchent, en convertissant un perchoir en un piége.

Ce dernier mode de chasse se pratique dans les tendues au moyen de raquettes, de lacets et de gluaux.

On nomme raquette un piége qui se détend quand un oiseau vient se poser sur un petit perchoir destiné à l'attirer et le faire prendre par les pattes; ce perchoir est placé le plus souvent à 60 ou 80 centimètres au-dessus du sol.

Le lacet à nœud coulant, tendu au moyen d'une branche flexible et faisant ressort, est un genre de raquette, pour laquelle un perchoir placé très-près de l'eau ou de la terre est encore une pièce principale.

On se sert aussi, mais plus rarement, de lacets simplement suspendus soit à la surface du sol, soit à différentes hauteurs; on les nomme le plus souvent collets, parce que l'oiseau se prend par le cou.

Enfin, les gluaux sont de petites baguettes de bois enduites de glu et fixées légèrement sur des branches, de manière à retenir l'oiseau qui se pose dessus et l'entraîner avec elles dans leur chute.

Avec les raquettes et les gluaux, on attrape les plus petits oiseaux; les lacets sont destinés aux plus gros et sont tendus, en général, sur le bord d'une fontaine, d'un ruisselet ou d'une flaque d'eau.

C'est sur le bord des eaux que l'on attrape le plus grand nombre d'espèces. On trouve principalement des insectivores dans les chemins, dans les sentiers et sur la lisiere des bois, tandis que l'on voit les petits granivores dans les plaines et dans les jardins. 
Ces explications sont, je crois, suffisantes pour faire voir que chaque mode de tendue a un but très-spécial et très-déterminé; avec le fusil on chasse tout, tandis que tel ou tel piége n'est destiné qu'à tel ou tel oiseau. Ainsi le piége à canard n'est pas fait pour les passereaux, la raquette pour le cormoran; sur le chardon on ne prend pas les rossignols, ni les chardonnerets dans le sentier de la forêt.

Essayons maintenant de déterminer la spécialité de la chasse connue sous le nom de tendue.

Les oiseaux, avons-nous dit, se portent de tous côtés pour boire et pour manger; or, plus il faudra multiplier leurs déplacements à la surface de la terre et de l'eau ou à de faibles hauteurs, plus ils devront chercher des perchoirs et plus ils seront exposés à être pris dans une tendue de raquettes, de lacets ou de gluaux.

On sait quelles sont les espèces de sylvains qui changent le plus souvent de place.

$\mathrm{Si}$, en se cachant, on peut observer les oiseaux pendant leurs repas ; si, quand on les tient, on examine leur taille, leurs proportions, leur organisme, leurs pieds, surtout leurs becs noinmés à si juste titre becs fins, et si l'on détermine les aliments qui ne sont pas encore décomposés dans leur estomac au moment de leur mort violente, on se convainc facilement que ce sont les plus petits des oiseaux insectivores.

En effet, ils ont pour mission d'eliminer les insectes infiniment petits et leurs œufs, qui sont toujours disséminés, isolés et cachés dans les herbes, lesmousses, les lichens et les feuilles des buissons, des taillis et des arbres. 
Beaucoup de ces insectes sont à peine visibles et saisissables. La cécidomyie est un moucheron de deux millimètres de longueur, le charançon a cinq millimètres, la pyrale a vingt millimètres; quant aux œufs, ils sont presque imperceptibles, tant par leur petitesse que par les lieux où la plupart sont déposés.

La recherche des petits insectes et de leurs œufs est donc bien difficile, surtout pendant les heures sombres du matin et du soir, des temps brumeux et pluvieux.

Quelquefois ils sont placés comme les plus menues graines que le chardonneret va cueillir, à l'extrémité d'une faible tige.

Pour échapper, il suffit qu'un insecte de la grosseur d'un puceron passe d'un côté à l'autre d'un brin d'herbe, ou qu'il se laisse tomber comme l'écrivain, vulgairement appelé gribouri; et, quand il voit ou entend un bec croquer son voisin, il sait très-bien mettre à profit toutes ses chances de salut.

Enfin, pour rassasier un oiseau mème de petite taille, il faut beaucoup de ces insectes et surtout de leurs œufs.

Aussi les petits insectivores sont-ils constamment en observation et en chasse ; ils volent, ils sautent, ils marchent, ils vont, ils viennent, ils montent, ils descendent, ils se tournent et se retournentdans tous les sens. C'est un mouvement perpétuel. Quelquesuns, comme le roitelet, changent de place 15 à 20,000 fois par jour.

Avec ce genre de vie comment ne pas ètre pris dans les raquettes. 
Aussi les états que nous avons produits dans notre premier mémoire démontrent que les petits oiseaux insectivores sont plus que tous autres sacrifiés dans les tendues?

Et cependantils détruisent considérablementd'insectes, qui, en se multipliant à l'excès, deviennent de dangereux ennemis pour les végétaux, et nous savons s'il y a quelque chose de comparable à la fécondité de la plupart des insectes : en très-peu de temps ils forment des légions, des armées innombrables; le puceron et le coccus, l'écrivain et le phylloxera sont là pour nous dire combien sont redoutables leurs invasions.

M. Ducuing estime à 300 millions les pertes annuelles moyennes que les insectes occasionnent à la France, et dans cette évaluation il ne comprend pas les ravages du phylloxera vastatrix. Des avis à peu près unanimes venus de tous les points de la France, il résulte, ajoute-t-il, que le nombre d'insectes augmente dans une région à mesure que décroît le nombre des oiseaux insectivores.

Ces derniers forment, ainsi que nous venons de le voir, un genre d'une spėcialité très-caractéristique. Pour tout homme il est facile de constater que, si la mésange, le rouge-gorge et la sittelle ne sont pas créés pour exercer les industries du ramier, du canard et de la chouette, ces derniers, ainsi que des centaines d'autres moyennes et grosses espèces d'oiseaux, sont généralement incapables de remplacer avantageusement la mésange, le rouge-gorge et la sittelle. En supposant qu'ils aient, ce qui n'est pas, les goùts et les appareils digestifs 
de ces derniers, ils sont trop lourds pour se poser sur une brindille et pour sauter d'un si petit perchoir sur un autre aussi flexible, trop gros pour se glisser et passer dans un fourré de feuilles comme la souris dans les herbes, ils ont la voilure trop grande pour voleter au milieu des branches, ils ne sont pas assez bien éperonnés pour essayer de grimper. Beaucoup d'entre eux qui, cependant, excellent à accomplir dans l'espace des déplacements longs, multipliés, deviennent impuissants quand il s'agit d'opérer de nombreuses et rapides évolutions dans les vides que traversent en tous sens les petites branches des arbres, des arbustes et des herbes, quand, en allées et en renues, en ascensions et en descentes, il faut, pendant une matinée dans un buisson, faire plusieurs kilomètres.

De plus, dans beaucoup de cas, les petits oiseaux insectivores suppléent les gros insectivores, les crapauds, les grenouilles, les lézards, les couleuvres, tandis que par l'infériorité de leurs modes de locomotion, ces derniers ne peuvent se substituer aux oiseaux.

Indépendamment de sa valeur générique chaque espèce de ces oiseaux a encore son importance particulière. Dans la première partie de cette étude nous avons déjà parlé de la mésange, et nous nous occuperons un peu plus loin du rouge-gorge; nos observations au sujet de ces deux espèces suffiront, je l'espère, pour justifier cette énonciation.

Or, par quoi les tendeurs remplaceront-ils ces admirables agents d'élimination? Combien faudrat-il d'appareils, d'ingrédients chimiques, d'liommes de service, d'argent et de temps pour procurer les 
mêmes avantages sur les rochers, dans les marais, les fourrés de la forèt, au sommet et dans l'intérieur des arbres, dans les airs et enfin partout?

Et l'on sait si la chair des oiseaux est une sérieuse compensation à la perte du travail de ce petit être. Qu'on en juge par le fait suivant que je dois à l'obligeance d'un homme fort honorable: "J'ai été ", m'a-t-il dit, "invité à déjeuner chez M. X....; nous étions douze à table. Après un repas que je croyais terminé et dans lequel avaient figuré un salmis de bécasses et un cuissot de chevreuil, on apporte des brochettes de petits oiseaux. Quatre des convives en mangèrent chacun six douzaines, les autres allèrent de deux à quatre, seul je m'abstins ».

N'est-ce pas le cas de citer ce passage du rapport de M. Bonjean : "Ce n'est pas sérieusement qu'on voudrait légitimer ainsi la destruction de ces petits êtres dont chacun fait à peine une bouchée. Est-ce aussi une nourriture que ces oiseaux-mouches de l'ancien monde, le troglodyte et le roitelet, qui ne sont qu'une bouffée de plumes ? non, ce n'est pas alimentation, c'est gourmandise brutale qu'il faudrait dire ".

Assurément tant de douzaines d'oiseaux auraient rendu de plus grands services à la société s'ils avaient continué à vivre pendant š, 10, $1 \ddot{3}$, ou 20 ans.

Les chiffres que j'ai produits dans la première partie de cette étude sont du reste assez éloquents pour éclairer et trancher cette question : 3,239 petits insectivores pris dans les tendues n'ont fourni que 22,743 gr. 85 de chair. Il faut détruire de 200 à 
250 roitelets pour en obtenir $500 \mathrm{gr}$. Il est bon de dire que, pour arriver à ce poids, je compte la peau aussi bien que la chair. Comme le rouge-gorge est un oiseau que l'on prend en grand nombre dans les tendues, je dirai plus loin quelques mots de son utilité ; en attendant, et puisque nous parlons en ce moment du poids de la chair, je livre à la méditation du lecteur quelques chiffres.

J'ai demandé à des tendeurs la permission de peser leurs rouges-gorges: 80 pesées m'ont donné en poids moyen, pour chaque individu, 17 grammes 20 centigrammes.

Maintenant, si je me reporte aux analyses que j'ai faites sur 200 espèces environ d'oiseaux, je trouve pour le rouge-gorge ce qui suit:

28 octobre 1871. - Poids d'un oiseau avant dissection, 16.50

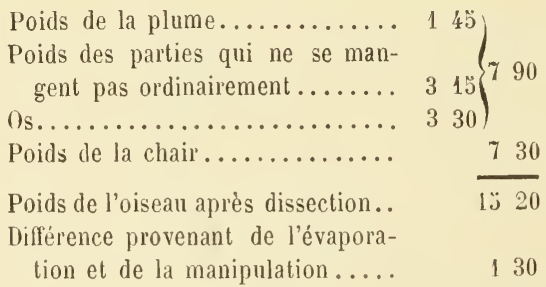

ǰ avril 187.5. - Poids d'un oiseau avant dissection. 15.80

Petites plumes....................

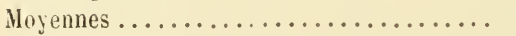

Grandes...........................

Appareils de l'élimination et de la transformation : larynx, pharynx, estomac, foie, reins, poumons, cœur, intérieur........

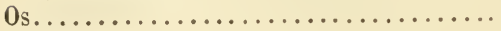

Contenu de l'estomac et des intestins......

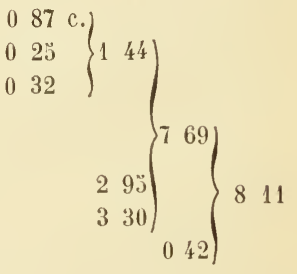

Chair du cou, du corps, des pattes et des

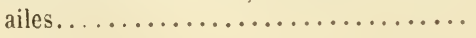

Différence provenant de l'évaporation et de la manipulation... 207 
Cette différence est plus grande que celle de la première analyse, parce que la deuxième opération est plus complète. Les chiffres ne sont euxmêmes que des totaux relatifs à des détails que je ne crois pas devoir porter ici. Au moins voit-on que la chair ne pèse que de 7 à 8 grammes.

II.

Des oiseaux de passage.

§ 1. - DE LA répartition des orseaUx a LA SURFace

DE LA TERre. des migrations, de leurs causes,

DE LEERS MOYENS ET DE LEURS EFFETS UTILES.

Pour justifier les hécatombes des petits insectivores, des tendeurs disent : Sans doute ces oiseaux rendent des services, mais ils peuvent devenir trop nombreux, et par cela même nous causer des préjudices.

J'ai déjà exposé qu'il y a moins d'oiseaux qu'autrefois et que nous n'en avons pas assez; j'ajoute que nous n'avons pas à redouter leur trop grand nombre.

La plupart de nos oiseaux émigrent en hiver, mais, en général, ils reviennent dans les lieux où ils ont été élevés. Il est même probable que dans leurs migrations, ils suivent souvent la même direction. Toutefois il y a à cette règle de merveilleuses exceptions, et il se fait de ces éliminateurs une répartition trop importante et trop rationnelle pour que nous n'en donnions pas l'explication. 
De mème que l'eau est transporlée des réservoirs de l'Océan dans toutes les directions de la terre sur les ailes des vents, comme disent les poëtes, et qu'elle tombe sous forme de pluie pour tout rafrầchir et laver; de même certains agents de l'élimination ayant forme d'oiseaux se portent à tire-d'ailes sur tous les points où le travail dont ils sont chargés devient opportun.

L'action de ces grandes forces de l'arrosement lerrestre et de l'élimination ne se produit pas au hasard, comme il semble à tant de personnes; les nuages et les oiseaux se distribuent providentiellement là où ils sont nécessaires.

Les lois de leurs déplacements sont absolues, immuables, et de mème qu'à l'aide des sciences de l'astronomie et de la météorologie, et en consultant dans un grand nombre d'observations les dépressions barométriques, on peut annoncer plus ou moins longtemps à l'avance les grandes variations atmosphériques; de même, à l'aide de l'ornithologie et d'observations suivies sur les diverses phases de la végétation et de la production des insectes et autres petits animaux, on peut s'expliquer et prévoir les grands déplacements et les migrations des oiseaux en général, et en particulier des sylvains.

Ainsi que nous l'avons déjà dit ailleurs, un principe capital en ces matières est le suivant : "L’élimination apparaît partout où les forces de la vie végétale ou animale se montrent en excès ou en décomposition, et aussitôt qu'elles ont besoin d'être partiellement déplacées, augmentées ou diminuées. 
Nous avons déjà, dans de nombreuses pages (1), donné les développements que comporte cette définition; cependant, pour rendre le présent chapitre plus intelligible par lui-même et sans recourir ailleurs, résumons en quelques mots ce que nous avons déjà exposé. Rappelons d'abord un premier principe.

Pour ne pas l'épuiser, il ne faut pas demander à une force plus qu'elle ne peut donner, à un homme de porter la charge d'un mulet ou de courir comme un cheval, à une poule de couver trente œufs, à un corbeau d'élever vingt petits, à un are de terrain de produire comme un hectare.

C'est en tenant compte de ce principe que l'ou plante, à une certaine distance les uns des autres, les choux dans les jardins, les betteraves dans la plaine, les peupliers dans les lieux boisés. En ces circonstances il faut que l'homme intervienne de sa propre main, soit pour planter, soit pour remplacer les plants morts, et il peut mème arriver que tous les plants périssent et, avec eux, les espèces.

C'est, par exemple, ce qui est arrivé pourla laitue Bossin. Un jour, en entrant chez un jardinier, cet éminent horticulteur fut frappé de voir des laitues grosses comme des choux etd'ailleurs fort bonnes, il s'empressa d'en demander de la graine. Après beaucoup d'hésitations, et après s'ètre assuré qu'il avait affaire à un savant, et non à un confrère qui lui ferait concurrence, le jardinier se décida à donner trois graines. Quelques années plus tard, etmalgré tous ses soins, il perdit la race qu'il avait créée ;

(1) Les oiseaux dans les Harmonies de la nature. 
désolé, il alla trouver M. Bossin qui l'avait conserrée et qui fut très-heureux de lui en rendre des graines. C'est en raison de cette aventure que cette laitue est connue et vendue dans le commerce sous le nom de laitue Bossin.

Dieu a prévu les négligences des hommes, et il a voulu, par l'intermédiaire d'agents indépendants de lui, de ses erreurs et de ses passions, revêtir les productions végétales et animales de la plus grande puissance, tout en assurant la conservation de leurs espèces. C'est pourquoi il a donné aux végétaux une force reproductive extrêmement considérable, à leurs graines et à leurs fruits le pouvoir de se conserver longtemps. De plus, cette reproduction a lieu chaque année.

La fécondité des petits animaux, disons-le en passant, n'est pas moins remarquable: beaucoup se reproduisent plusieurs fois dans un an.

Cependant la propagation a aussi ses excès; pour y remédier Dieu a créé et a fait intervenir d'autres forces, celles de l'élimination, pour ne laisser survivre qu'en nombre utile les végétaux et les animaux et sans jamais compromettre leurs espèces. "Tantòt par l'action du froid, de l'humidité et du vent, l'élimination opère de véritables razzias, mais seulement dans telle ou telle contrée, telle ou telle région et par intermittence ; tantôt, quand les végétaux sont trop rapprochés, elle fait succomber les plus faibles sous l'action des plus vigoureux. Le plus souvent, elle se porte d'un point à un autre pour produire en détail et d'une manière avantageuse tous ses efforts.

"Les insectes et les oiseaux qui sont chargés de 
ce dernier travail et de répartir l'élimination sur tous les points où elle devient particulièrement nécessaire, sont conformés et outillés de manière à attaquer, dans certains pays ou certaines parties du territoire, tels ou tels êtres, telles ou telles portions de ces ètres pour les détruire et les transformer immédiatement.

"C'est pour accomplir la partie la plus difficile et la plus importante de cette tâche, que les oiseaux ont le privilége de faire des déplacements très-multipliés, très-rapides et très-éloignés, malgré tous les obstacles ".

De ce qui précède, il suit donc que là où il n'y a pas excès ou décomposition des végètaux ou des animaux, l'élimination n'a pas à intervenir.

Or, quand l'automne est venu mettre un terme à la végétation de l'année, qu'il a amené la première et principale des décompositions végétales et animales, que sous l'action de l'hiver la nature se repose et se prépare à l'enfantement du printemps, il se produit pour beaucoup d'éliminateurs un chòmage qui devrait amener une famine générale et même faire périr beaucoup d'espèces, si le Créateur n'y avait pourvu.

Par exemple, quand les feuilles des arbres sont tombées et desséchées, et que les herbes des champs sont fanées et à demi décomposées, quand les fleurs ont disparu, que les fruits ont été cueillis ou qu'ils sont pourris, les chenilles, les criquets et beaucoup d'espèces de diptères ne peuvent plus vivre.

Aussi un grand nombre d'éliminateurs, tels que les insectes, les batraciens et les reptiles, ont le 
sang relativement froid et nous font éprouver une sensation désagréable quand nous les touchons. En s'enfonçant et en restant en terre assez profondément, ils peuvent échapper aux froids de l'hiver, et, plongés dans uu profond engourdissement, ils vivent sans manger; beaucoup ne se réveillent qu'au souffle du printemps, quand les travaux de l'élimination vont recommencer; quelques-uns de ceux qui peuvent encore trouver un peu de nourriture sortent quelques instants de leur léthargie quand ils sont passagèrement et vivement pénétrés par l'ardeur du soleil d'hiver.

On s'expliquerait difficilement qu'en raison de leur constitution, de la température de leur sang qui atteint le maximum de la chaleur animale, les oiseaux eussent pu être soumis à un pareil régime, et d'ailleurs leurs services n'eussent été utilisés que pendant une partie de l'année.

On comprend au contraire très-bien qu'une constitution toute privilégiée leur ait été donnée, que non-seulement ils aient reçu en partage tous les modes de locomotion des autres animaux, mais qu'eux seuls de tous ils aient été gratifiés de la merveilleuse puissance duvol et d'un revêtement de plumes aussi chaudes que légères, que pour leur mission il leur ait été accordé des instincts et des organes presque infaillibles, qu'ainsi pendant l'hiver les uns soient restés dans leur pays natal, que beaucoup aient pu aller porter leurs industries et leurs services dans d'autres contrées et en revenir au printemps, et qu'enfin il ait été possible à tous, à toute époque, d'opérer de grands déplacements pourcompléter et régulariserleséliminations. 
Ces aptitudes remarquables frappent très-vivement l'observateur, même au milieu des magnificences de la nature.

L'architecture des nids, en mettant en relief la supériorité de l’oiseau, nous fait par cela même déjà concevoir à quels puissants instincts il obéit, soit quand il se fixe longtemps en un lieu, soit quand il opère ses plus grands déplacements.

D’abord la spécialité du travail et du lieu où il s'accomplit était une condition de succès pour les éliminations qui lui sont confiées; aussi les mêmes oiseaux ne se trouvent pas partout. Des 8,000 espèces et plus, š21 seulement ont été observées en Europe (1).

Dans notre vallée de la Marne, nous avons le moineau domestique, tandis que le moineau soulcie, qui s'y montre très-accidentellement, est commun en Espagne. Parmi nos sédentaires d'été, nous comptons la grive chanteuse et la draine, tandis qu'à la mème époque le mauvis et la litorne nichent dans le nord.

Chaque espèce sédentaire est comme parquée dans une région plus ou moins grande comprenant souvent des millions d'hectares, et elle ne se reproduit jamais en dehors de ces limites.

De plus, chaque famille aime à revenir au lieu de sa naissance, et elle ne s'en éloigne que par nécessité.

Cet amour du même lieu se concilie avec l'impérieux instinct qui porte l'oiseau à accomplir ses migrations et ses retours.

(1) Ornithologie européenne, par Degland el Gerhe. 
Tout au moins ces actes si extraordinaires de sa vie s'expliquent partiellement.

L'oiseau évite la douleur, comme tout animal, et il recherche la jouissance. Il se donne donc le moins de peine possible, et il se porte de préférence dans les contrées et dans les lieux de sa circonscription où il y a surabondance de nourriture. C'est ainsi que les éliminations sont si profitables à la richesse publique.

L'impressionnabilité de son corps est également calculée de manière que dans les lieux où, selon le temps et la saison, il doit résider, il ne souffre pas plus du froid et de la chaleur que de la faim. Il possède ainsi en lui une sorte de thermomètre et de boussole à l'aide desquels il sent, quand il doit se fixer ou passer. Les gelées printanières ne surprennent que peu d'hirondelles.

Quelques oiseaux n'émigrent pas; en voici la raison :

Rien n'égale la légèreté et la chaleur des plumes. Elles servent à composer la partie la plus chaude de nos lits; au moindre des désirs de l'oiseau elles se soulèvent pour laisser arriver l'air frais, ou elles se plaquent et se resserrent pour contenir et développer la plus grande chaleur. A l'approche de l'hiver, beaucoup d'entre elles s'allongent, se complètent, et le duvet qui recouvre la peau s’épaissit. C'est ainsi que la perdrix et le moineau domestique ne nous quittent pas même au plus fort de la mauvaise saison.

Les plus grandes distances n'effraient pas l'oiseau.

Par la rapidité et la grâce de son vol, il est l'image vivante de la pensée. 
La ténuité de la proie, et même l'obscurité, ne le déconcerte pas.

La vue de beaucoup d'oiseaux possède, avec une longue portèe, la pénétration d'un microscope. Les ducs et les chouettes ne chassent que la nuit.

Pour beaucoup la tâche d'élimination est variée de telle sorte que quand la nourriture principale vient à manquer, ils ne se trouvent pas dans l'alternative de mourir de faim ou d'émigrer. C'est ainsi que le merle, la litorne et l'accenteur-mouchet se nourrissent complétement de baies pendant les neiges.

Cet admirable organisme de l'oiseau suffirait donc pour faire deviner le ròle supérieur, qui lui est assigné parmi les agents de l'élimination et dans les grandes harmonies de la création.

Il nous explique comment un être de proportions si petites est comme rivé à d'aussi grands devoirs et sert si parfaitement nos intérêts.

Une jeune hirondelle de fenêtre, quittant son nid vers le 30 août, est prête à partir deux mois après pour la Guinće et le midi de l'Afrique ; son corps n'a pour cube que trois centimètres, et pour poids que 17 grammes, et cependant dès son premier voyage elle pourra jeter un regard de pitié sur notre voierie, nos ponts, nos bateaux, nos vaisseaux, nos ballons, nos bagages et nos provisions de route, nos cartes géographiques et nos boussoles. ll lui arrivera, à huit jours d'intervalle, de travailler en Champagne et au Sénégal, de se mettre au service d'un blanc et d'un noir et de se repaître de cousins et de moustiques.

Autre exemple: Une grande outarde, dont j'ai 
raconté l'histoire (1), la dernière jeune que l'on ait ćlevée et même vue en Champagne, était, au moment des passages, tellement agitée et insupportable, que son propriétaire se vit obligé de s'en défarre malgré son attachement pour elle.

Les cailles en cage s'agitent aussi beaucoup au moment de la migration.

Faisons maintenant ressortir la nécessité des migrations par les températures des divers milieux.

Si nous portons notre attention sur les parties de notre globe connues sous les noms d'Europe et d'Afrique, nous verrons que leurs climats et leurs productions sont très-varies, et que ceux de l'Europe sont échelonnés du nord au midi et de l'orient à l'occident, de telle sorte que le travail de beaucoup d'espèces d'oiseaux peut être utilisé au profit des peuples fort éloignés les uns des autres.

La tempéralure moyenne des régions polaires semble comprise entre $25^{\circ}$ et $38^{\circ}$ au-dessous de zéro (2); elle s'est abaissée jusqu'à $40^{\circ}$ à $50^{\circ}(3)$.

Dans la zone torride la température moyenne est comprise entre $27^{\circ}$ ว et $29^{\circ} 6$ au-dessus de zéro (4);

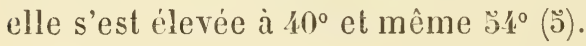

(1) Lettre reproduite par mon savant ami vincelot dans son ouvrage intitulé : Les noms des oiseaux expliqués par leurs mours, t. II.

(2) Régions polaires. - Les diverses expéditions qui ont été faites vers le pôle boréal, dans ces dernières amées, out fourni un grand nombre d'observations précieuses, desquelles il semble résulter que la température du pôle lui-mème serait comprise entre $25^{\circ}$ et $38^{\circ}$ andessous de zéro. (Eléments de physique, par Pouillet (1856), t. II, 679.

(3) Lans les régions polaires, le capitaine Parry a observé quelquefois des températures de $40^{\circ}$ à $50^{\circ}$ au-dessous de zéro. (Ilid., p. 681.)

(4) L'ensemble des observations indique que la température moyenne est, sous l'équateur, comprise entre $27^{\circ}, 5^{\circ}$ et $28^{\circ}$. Cependant, pour Pondichéry, elle est de 296. (Ibid. p. 678.)

(5) Il parait aussi que les plus hautes températures de l'air qui aient 
Comme on le voit, ces chiffres donnent environ $100^{\circ}$ pour la limite des variations extrêmes de température que l'on puisse éprouver à la surface de la terre.

La moyenne de la France est de 12 (1); à Paris, celle de trente années, de 1823 à 185̋, a été de $10.80 ; 2)$.

Sous la mème latilude la température varie également d'après les différences d'altitude. Elle diminue à mesure qu'on s'élève dans l'air. Cette diminution est en moyenne d'un degré par 150 mètres au plus en été, par 200 mètres en hiver. Il en résulte que vers 4,000 mètres d'altitude, aux moments les plus chauds de l'été, vers 3,000 ou 2,000 au printemps ou en automne, à moins de 1,000 mètres en hiver, on est sûr de trouver, en montant dans l'atmosphère, la température de la glace (3).

Ces faits se remarquent, par exemple, sur les quatorze sommets les plus élevés des Alpes qui ont chacun, au-dessus du niveau de la mer, de 3,936 à 4,810 mètres, et surtout sur le Chamalari de la chaîne de l'Himalaya en Asie qui les dépasse encore de 5,064 mètres; comme le Chamalari, le Mont-Blanc est couronné de neiges perpétuelles.

Les différences de climat dépendant de la température de la longitude, de la latitude et de l'altitude sont encore modifiées par la direction des vents dominants et des chaînes de montagne, par le voisi-

été observées sous la zone torride se sont élevées de $40^{\circ}$ à $50^{\circ}$ et que Lyon et Bitchnic ont même observé une température de $54^{\circ}$ à l'oasis de Iourzouch. (Ibid, p. 681.)

(1) Bouillet, Dictionnaire.

(2) Pouillet. (Ibid., p. 676.)

(3) A. Michel. 
nage de la mer ou de marais considérables, de rivières, de forêts, par l'exposition, etc.

Les variétés de sol et de climat ont naturellement donné lieu à des espèces variées de plantes, d'insectes et de petits animaux qui s'étagent, surtout du nord au midi.

Quel géographe, quel agriculteur pourrait indiquer à l'oiseau ce qu'il a de mieux à faire pour se créer des facilités de vivre et rendre en mêıne temps les plus grands services aux peuples divers et souvent inconnus que forment 220 millions d'Européens et 106 millions d'Africains (1)?

Heureusement l'oiseau peut se passer du concours des hommes et mème de leur science, il ne leur demande qu'une chose, de ne pas être traité en ennemi. Il est pourvu de tout ce qui lui faut pour fonctionner suivant les desseins de Dieu comme l'ouvrier, l'apôtre, et le prédicateur de sa Providence.

Dès le 28 juillet, les martinets laissent aux hirondelles d'écurie, de fenêtres et de rivage, le soin d'éliminer les diptères, et ils transportent leurs industries en Afrique, qui regorge alors d'insectes ailés. Pour des raisons du mème genre, la cigogne traverse notre pays en août, la tourterelle nous quitte en septembre, le rouge-gorge passe en septembre et octobre, le canard pilet en novembre.

Mais, en émigrant, certains genres nous laissent, pour les représenter en leur absence, quelques-unes de leurs espèces. Pendant l'hiver, les becs-fins sont

(1) Bouillet, aux mots Population el Europe. 
suppléés par l'étourneau, le merle, le rouge-gorge, l'accenteur-moucliet.

Après le départ des tourterelles les ramiers restent.

La draine, qui nous quitte généralement en octobre et en novembre, est remplacée par la litorne du nord, qui travaille et jacasse dans nos champs et nos prés jusqu'en mars.

Le climat maritime de l'0céan est quelquefois très-sensiblement plus clément que celui de l'Orient, ce qui nous vaut alors la visite du beau jaseur de Bohême en décembre et de la grande outarde en janvier.

Pour des raisons de climat et surtout à cause de la proximité, nous voyons aussi dans nos vallées de la Marne des oiseaux du littoral de l'Océan, des goëlands, des sternes, d'autres palmipèdes, quelquefois même le macareux-moine et l'huitrier-pie.

L'accenteur des Alpes (accentor alpinus) descend quelquefois pour nous visiter dans la mauvaise saison.

Les périodes froides ou très-froides de l'automne, de l'hiver et du printemps, sont souvent entrecoupées de journées relativement chaudes pendant lesquelles une partie de la végétation reparaît et avec elle certains insectes. Ces variations ainsi que les vents défavorables amènent les oiseaux à modifier leur marche, à stationner, à se porter de côté, à revenir en arrière, en sorte qu'aucune contrée ne reste inexplorée.

L'hiver de 1873 à 1874 a èté extrèmement doux ; alors les morelles et les grèbes-castagneux, qui vont presque toujours hiverner dans le midi, ne nous quitterent pas. 
Quand la température s'élève et se continue au frintemps, des oiseaux du midi, tels que le cysticole ordinaire, la fauvette mèlanocéphale, le rollier commun, le guêpier, poussent des reconnaissances dans notre vallée, quelques-uns s'y établissent même, quand les ressources de la vie leur semblent abondantes; c'est ainsi que l'on a trouvé sur nos marchés, au printemps, la spatule, l'ibis fascinelle, l'avocette, et que le canard nyroca et la sterne-leucoptère niclıent sur nos étangs.

Entre les variétés de climat et de production et l'apparition de certains oiseaux il y a en général une concordance si grande, une relation si intime de cause à effet, que la précocité des passages des oiseaux du nord est le plus souvent l'annonce de l'hiver, et leur retour la bonne nouvelle du printemps.

Ces répartitions générales d'éliminateurs ne s'accomplissent jamais sans porter avec elles de grands enseignements et des joies nouvelles à tous ceux qui ne sont ni aveugles, ni sourds, ni indifférents.

Voyez cette bande joyeuse de chardonnerets, quelle ardeur et quelle vivacité dans ces évolutions ! Elle s'abaisse, et en un instant des touffes de chardons desséchées, ridées, hérissées d'aiguilles se couronnent de fleurs qui scintillent, frétillent et chantent.

Ecoutez encore, d'autres voix se font entendre, timbrées comme le cuivre, c'est un passage de grues qui sont parties des régions polaires; c'est encore dans l'espace la vie portée sur de gracieuses voiles; ces oiseaux formant le triangle d'une flìche, fendent l'air et les nuages. Eux aussi avec beau- 
coup d'autres proclament à leur façon, comme.au son de la trompette, du haut des nues, les mystérieuses splendeurs de la création, et alors qu'ils ont déjà disparu, leurs notes adoucies viennent encore animer les bruissements des vents.

Quand les feuilles d'automne sont tombées et que des âmes en si grand nombre ont quitte leurs familles éplorées, ces austères harmonies de l'hiver, le mouvement, la manifestation de la vie dans l'espace, dans les hauteurs du ciel, sont-elles sans poésie, surtout pour nos plus chères espérances?

A la grandeur de nos aspirations nous sentons que nous ne sommes pas créés pour nous complaire dans les sphères de la vie matérielle et dans les vulgarités de la vie. Ce serait donc une erreul que de rapetisser les questions, ce serait un malheur que de ne pas apprécier les joies d'esprit et de cœur dont nous sommes redevables aux oiseaux de passage.

Tous les déplacements, toutes les manœuvres dont nous venons de parler, s'expliquent plus encore si l'attention se porte sur certains chiffres.

J'ai calculé qu'une hirondelle rustique a franchi 8,882 mètres en deux minutes, que dans une journée de juin cet oiseau fait 600 kilomètres en un jour, et que pendant le même laps de temps une mésange bleue a parcouru 22,900 mètres.

Or, l'Europe a environ 4,000 kilomètres de long sur 3,500 de large ; la longueur de l'Afrique est de 7, ,ั0 kilomètres.

L'étendue de la France est de 1,06ł kilomètres du nord-ouest au sud-est, et de 924 kilomètres du 
sud-ouest au nord-est; sa superficie est de $52,30 ð, 744$ hectares.

kilomètres.

Il y a du liltoral de la France à la Corse 130

De la Sardaigne à l'Afrique......... 180

De la Sicile à l'Afrique............ 1 ๖ 0

Et d'une côte à $\dot{y}^{5} l$ 'autre de Gibraltar.... 15

En multipliant nos observations, nous sommes donc amenés à reconnaître et par les faits et par le raisonnement qu'il se produit à la surface du globe, et particulièrement en Europe et en Afrique, une répartition des oiseaux en parfait rapport avec la régularisation des éliminations végélales et animales, et je reste persuadé que plus ces questions, en ce qui concerne surtout l'Europe et l'Afrique, seront étudiées comme elles doivent l'être, plus on pourra se convaincre de cette vérité et répéter cette phrase d'une lettre que son Eminence le cardinal Donnet me faisait l'honneur de m'écrire le 28 août 1872 : “ Les oiseaux mettront encore longtemps à l'épreuve la sagacité des savants, mais ce qu'on peut affirmer sans crainte, c'est que plus on les étudiera, plus on sera frappé de leur utilité ».

\section{§ 2. - Utilité des oISEAux de passage.}

Peut-être, au jugement 'de quelques lecteurs, nous sommes-nous trop étendu sur les harmonies de la répartition des oiseaux à la surface du globe; mais cette étude intéressante était nécessaire, au moins à l'état d'ébauche, pour jeter quelque lumière sur le sujet que je me suis proposé de traiter ici. Revenons donc aux tendues. 
On domne comme argument en faveur de ce genre de chasse, qu'il s'agit sculement de prendre des oiseaux qui ne font que passer dans notre pays.

D'abord, je ne connais pas de moyen de préserver les oiseaux sédentaires des piéges qui sont tendus aux oiseaux de passage. Ensuite, et on a pu s'en convaincre, ces derniers ne vont pas d'un trait aux frontières de l'Italie et de l'Espagne. Ils stationnent sur tous les points de la France. Dans notre région, certaines de leurs espèces séjournent aussi et plus longtemps que quelques-unes de nos sédentaires. Les premiers martinets nous sont arrivés cette année le 24 avril, et les derniers ont disparu le 28 juillet, tandis que les passages de rouges-gorges durent deux mois, rien qu'en automne ; c'est même par ces considérations que les tendues sont autorisées en général du $\mathbf{t}^{\mathrm{er}}$ septembre au $\mathfrak{1}^{\mathrm{er}}$ novembre. Au printemps, les oiseaux parcourent également pendant longtemps nos contrées en se rendant vers le nord.

A en juger par le nombre, la durée et l'ordre des passages, ces travaux du printemps et de l'automne ne sont pas moins remarquables par leur spécialité que ceux qu'accomplissent nos sédentaires d'été ; les uns et les autres sont absolument nécessaires à l'équilibre des forces végétales et animales et à la richesse agricole. Le nombre des insectes est trèsgrand en automne; c'est alors surtout qu'ils sont surabondants et qu'ils arrivent ainsi à former contre nous une armée d'ennemis d'autant plus dangereuse, qu'ils vont en partie prendre dans le sein de la terre leurs cantonnements d'hiver et pre- 
parer pour le printemps suivant de nouveaux et innombrables contingents, quelquefois une véritable invasion.

Or, les petits oiseaux insectivores forment également une armée, mais une armée d'alliés qui combattent pour nous, et ils restent sur le champ de bataille jusqu'à ce que les derniers de nos ennemis aient disparu dans la mousse, les herbes, les écorces d'arbre et surtout dans le sein de la terre.

En automne, et principalement en octobre, nous avons souvent, on le sait, des alternatives de beau et de mauvais temps, de chaleur et de froid, et, selon les circonstances, les insectes se montrent ou se cachent; se produit-il une douce température, un rayon de soleil, ils font une sortie, alors passe une escouade d'oiseaux insectivores qui s'abat sur eux; comme les passages de nos alliés se succèdent sans cesse pendant deux mois, beaucoup de nos ennemis qui, pour une raison quelconque, ont échappé aux uns, sont croqués par les autres.

Un grand nombre de sédentaires sont à cette époque-là aidés ou suppléés par des oiseaux de même espèce venus du nord, et même par d'autres espèces ; c'est ainsi que la litorne arrive en général, ainsi que nous l'avons dit, quand la draine part.

Il y a même des espèces de Suède, d'Angleterre, de Hollande et de Belgique qui, pendant tout l'hiver, nous apportent une industrie pour laquelle nos sédentaires d'été n'ont pas d'aptitude ; tels sont les roitelets et la petite mésange noire.

Enfin, ce serait perdre son temps que de faire des tendues pour les oiseaux de passage irrégulier ou accidentel, coinme l'accenteur alpin; on prend 
presque toujours des oiseaux de double passage régulier, ceux qui chaque printemps viennent re prendre leur tâche; alors la chaleur printanièr qui les ramène dans nos pays fait également reparaître les insectes et met encore ceux-ci en présence de leurs éternels ennemis; en sorte que cer taines espèces d'insectes qui échappent en automne sont atteintes au printemps. A cette dernière époque la fauvette grisette, qui mange deux pucerons, mâle et femelle, peut par ce seul fait nous avoir évité un quatrillon de pucerons.

Il se trouve de la sorte, et c'est un fait très-remarquable, que les insectes, qui pendant un an ont pullulé à l'excès, ne sont détruits, avant leur rcproduction de l'année suivante, qu'à l'époque de l'automne et du printemps, c'est-à-dire grâce surtout aux oiseaux de passage.

Ainsi donc, dans le pays mème où une tendue est établie, les oiseaux de passage ne sont pas moins essentiels que les oiseaux sédentaires. Les uns et les autres ont des spécialités d'époques et de mode de chasse. Les oiseaux de passage sont les travailleurs de l'automne et du printemps, ils complètent et régularisent les travaux de nos sédentaires d'été, et les bienfaits de l'élimination ne nous sont assurés que par le concours de tous.

En royant ce qui se passe dans un autre ordre de choses, nous trouvons des analogies, qui, a elles seules, feraient déjà deviner cette providentielle répartition du travail des oiseaux.

Dans un atelier bien organisé comme celui d'horlogerie, il y a un ouvrier chef ou un contre-maître qui vérifie les travaux partiels. 
Dans une exploitation agricole rien ne se fait bien et ne se complète sans la main ou au moins l'œil du maître.

Dans toutes les grandes administrations publiques il ya, au-dessus des employés ordinaires, les vérificateurs et les inspecteurs qui rayonnent, les uns simplement dans tel ou tel arrondissement, tel ou tel département, les autres dans tout l'Etat. Les Receveurs de l'Enregistrement ont au-dessus d'eux des vérificateurs et des inspecteurs; nous voyons, au-dessus de la police communale, la haute police; souvent même les inspecteurs sont obligés de prendre le train-poste.

Un ne s'explique pas que, pour le plus grand profit de tous ceux qui travaillent en commun, les ouvriers d'élite ne soient pas chargés d'inspecter, de rectifier et de compléter le travail des autres.

Dans la nature Dieu a pourvu à des besoins du même genre; d'innombrables éliminateurs de végétaux et d'animaux sont pour ainsi dire vérificateurs et inspecteurs. On dirait qu'ils prennent une espèce de train-poste, celui du vol, pour se transporter partout où leur intervention devient nécessaire. Dieu, qui a créé des hommes supérieurs pour guider et protéger les autres, l'architecte pour diriger le maçon, le docteur pour éclairer l'ignorant, n'a point laissé les innombrables éliminateurs sans supérieurs chargés de régulariserleurs travaux.

Par ces considérations on voit que les oiseaux de passage ne sont pas moins utiles que les autres et qu'ils sont, dans l'économie de l'élimination, des instruments nécessaires. 
C'est donc à tort que les législateurs de 1844 ont semblé en douter, et il importait d'autant plus d'entreprendre la réhabilitation de ces serviteurs de l'homme.

Je me suis demandé aussi ce que des auteurs peuvent entendre par espèces erratiques. On s'explique qu'un oiseau, surpris par la tempête et la nuit, ou entraîné par son ardeur, soit un instant dévoyé ; mais on ne comprendrait pas que des espèces fussent condamnées à se mouvoir ordinairement en dehors des lois de répartition dont nous avons parlé, et du reste les faits et les observations n'autorisent nullement des interprétations de ce genre. Il est donc bon de ne pas employer l'expression d'erratique en lui conservant sa signification naturelle, et alors il convient encore moins d'en faire un mauvais usage.

\section{§ 3. - INTERVENTION DE L'HOMME EN FAVEUR DES oIsEAUX DE PASSage.}

Nous avons dit que les oiseaux en général et ceux de passage en particulier devaient être et sout des régulateurs de l'élimination.

Mais pour la vie des hommes une loi impérieuse est celle du travail. Partout et toujours ils doivent intervenir et travailler pour obtenir de la nature tout ce qu'elle peut leur offrir de plus avantageux. Quand ils viennent habiter des contrées vierges, ils ont le droit et le devoir d'en modifier les productions indigènes au moyen de la culture. Par cela même qu'ils deviennent les ouvriers et les directeurs de la transformation des produits naturels, 
il leur incombe également la tâche d'y modifier parallèlement les forces de l'élimination, car, ainsi que nous l'avons vu, les forces de la production et de l'élimination doivent toujours parfaitement concorder entre elles pour que la richesse agricole atteigne sa plus grande valeur. Ainsi l'homme devient régulateur des éliminations. C'est donc pour lui un devoir d'étudier la nature de leurs forces et deleurs agents, et, selon les circonstances, de modérer l'action des uns et d'activer celle des autres.

Pour ne pas exposer les plantes du midi, qu'il transporte dans ses jardins, à des éliminations trop considérables que produirait le froid, il les remisera en hiver dans une orangerie ou dans une serre. Il plantera à l'abri du vent ses meilleurs arbres. Il emploiera les procédés que lui conseille la science pour faire périr des insectes devenus trop nombreux. Il fera la chasse à certains oiseaux de proie, pour qu'ils ne détruisent pas le gibier, et les oiseaux qui sont ses meilleurs auxiliaires comme éliminateurs; il s'opposera au dénichage et à la chasse à la tendue.

C'est pour ne pas s'être suffisamment inspiré de ces principes et avoir en ces matières laissé à la libre initiative de chaque individu le droit d'agir d'après son intérêt particulier, ses caprices et son ignorance, que la France a fait et fait chaque jour des pertes immenses, que tel homme, telle commune et tel département sont victimes des erreurs et de l'incurie de leurs voisins.

Quelques exemples suffiront pour expliquer combien sont vraies ces assertions. 
Le pâturage des terrains incultes de la Champagne procurant très-peu de profit, des propriétaires pensèrent qu'il y aurait avantage à les planter de pins sylvestres. Seulement, au lieu de n'employer que des plants provenant de semis faits dans le pays, ils en acheterent dans le nord, et avec ces arbustes fut importé le lopyrus pini. En Ecosse et en Irlande cet éliminateur des feuilles du pin est contenu par les influences de la température et par certains ennemis au nombre desquels se trouvent le roitelet huppé, le roitelet triple bandeau et la mésange noire. Transporté sous un climat différent et plus chaud, il s'est trouvé soustrait à l'action de ses éliminateurs naturels, et il s'est multiplié de telle sorte qu'il s'est répandu dans la plus grande partie des sapinières. Il a attaqué surtout les jeunes plantations ; le $1^{\text {er }}$ mai 1872, j'ai traversé sept cents hectares de sapins âgés de 30 à 40 ans et complétement dépouillés de leurs feuilles. On eût dit que ce bois avait été incendié ; un certain nombre d'arbres moururent, les autres sont en ce moment si languissants que le propriètaire hésite à les conserver plus longtemps.

Or, on a remarqué, dans quelques pays, que les mésanges percent les cocons du lopyrus pini et qu'elles aiment à en extraire et à manger les larves. Seulement sur les côteaux de la Champagne il n'y a pas d'eau en été, pas de trou dans lequel un oiseau puisse nicher, pas d'arbres des essences indigènes sur lesquels la mésange trouve un appoint de sa nourriture ordinaire, et ainsi l'intervention de cet oiseau de bonne volonté est très-difficile.

Mais le mois d'octobre arrive, et avec lui le roite- 
let huppé, le roitelet moustache et la mésange noire. Ces oiseaux du nord se répandent alors dans les sapinières et y travaillent sans relâche pendant six mois. Ils viennent ainsi réparer en partie l'imprévoyance des planteurs de sapins. Mais pour cela il importe qu'ils ne soient pas pris aux tendues.

Quelques roitelets et mésanges noires sont déjà restés en Champagne pour nicher.

En août 1873, des cigognes se sont arrêtées dans une sapinière du canton de Marson (Marne) et ont passé plusieurs jours à manger des chenilles du lopyrus pini.

Autre erreur dont les conséquences sont effrayantes: si d'Amérique en France on avait importé des pépins et non des pieds de vigne, on ne nous aurait pas amené le phylloxera.

L'insecte qui attaque le bois des arbres, n'est pas en général le même que celui qui détruit sa graine.

Ainsi que le dit M. Godron, " on a introduit en Europe par graines et non par plants, le platane, le maronnier d'Inde, le catalpa, etc., et pour cette raison ces arbres ne sont pas atteints par les insectes qui les rongent dans leur pays natal.

Toujours est-il que le phylloxera a pris possession d'un grand nombre de vignes du midi de la France, et que l'on a signalé ses envahissements en Suisse, en Autriche, en Portugal, en Grèce et dans les serres d'Angleterre et d'Irlande.

N'étant pas contenu par ses éliminateurs naturels, trouvant dans le midi des espèces de vignes beaucoup moins vigoureuses que celles de l'Amérique du Nord, il commet des ravages tels que le gouver- 
nement a offert 300,000 francs à celui qui trouvera le moyen de préserver efficacement la vigne de ce nouveau fléau.

Si des oiseaux peuvent rendre quelques services soit en happant le phylloxera aumoment où il s'élance de terre à l'état ailé, ou même quand il marche sur le sol, soit en croquant des œufs déposés sur le vieux bois des souches de vigne (1), ces oiseaux ne peuvent être que de petits insectivores du genre des mésanges et des becs-fins, les éliminateurs par excellence des insectes qui attaquent les plantes arborescentes ou ligneuses.

Dans la vallée de la Marne nous ne connaissons le phylloxera que par les relations des journaux du midi ; mais nous avons à nous méfier de la pyrale et de l'écrivain. L'un et l'autre ont déjà causé de grands préjudices en Bourgogne et en Champagne; cette année, l'écrivain vient d'apparaître sur les bordures du département de la Meuse, notamment à Ancerville et à Nettancourt, et il a déjà commis des ravages très-remarqués des vignerons. C'est donc le moment d'attirer et de protéger les petits oiseaux insectivores. Des nids artificiels pre-

(1) M. Balbiani et Boiteau ont observé que le phylloxera sexué, dérivé de l'insecte ailé, pond son ceuf au mois de septembre, sur le vieux bois de souche de vigne, dans la partie qui est située hors de terre. Cet œuf, qu'ils ont appelé œuf d'hiver, parce que son éclosion n'a lieu qu'au printemps suivant, produit des générations extrèmement prolifiques. Il n'en est pas de même des phylloxeras qui passent l'hiver sur les racines de la vigne; ils sont exclusivement composés de femelles parthénogènes, qui ont épuisé une grande quantité de leur fécondité par les pontes de l'année précédente. L'œuf d'hiver est donc le seul à redouter, et il importe absolument de le détruire.

Ramier, délégué de l'Académie des sciences. (Journal de l'agrieulture, 11 mars 1876, p. 431.) 
parés en été pour les mésanges, des buissons comme les groseillers laissés aux fauvettes pour nicher, des arbres et arbustes à baies qui fournissent aux insectivores un appoint de nourriture parfois indispensable sont autant de moyens bons à recommander, d'autant que dans les meilleurs sols on a fait disparaître tout ce qui gêne la vigne.

Dans le même ordre de choses, il est encore d'autres faits qu'il importe de signaler.

On a arraché complétement dans les meilleures plaines, comme dans les meilleurs vignobles, les buissons et les haies, et ainsi on a éloigné les oiseaux qui y nichaient ou qui s'y arrêtaient en passant.

La trop grande liberté de défricher a eu pour résultat de déboiser les montagnes, d'envaser le lit des fleuves et de favoriser les inondations. Le domaine forestier de la France n'est plus que de $8,593,866$ hectares; ces forêts occupent les seize centièmes du territoire.

En même temps que disparut une partie des forêts, la reproduction des sylvains diminua d'une manière très-sensible. Par suite elle n'a plus fourni, comme autrefois, un contingent annuel capable de répartir ses ouvriers en très-peu de temps dans tous les lieux où il y a des vides à combler, des suppléments de travaux à exécuter.

N'est-il pas surabondamment expliqué combien il est opportun d'étudier et de faire connaître les admirables lois de l'élimination, comme aussi d'intervenir à tout prix pour favoriser l'équilibre de ses forces et en assurer tous les bienfaits?

Trop d'hommes sont maintenant disposés à ne 
pas tenir compte des traditions. Fascinés par le mirage du progrès, ils quittent sans hésitation les voies dans lesquelles nos ancêtres sont entrés et restés à la suite d'observations séculaires, ils s'élancent en dehors des lois providentielles de l'ordre physique et moral, ils entraînent avec eux les ignorants et les indifférents; qu'attend-on pour les arrêter?

Il n'y a pas jusqu'aux hirondelles qui maintenant ne soient traitées comme des animaux malfaisants. Ces oiseaux, les plus utiles de tous, que la tradilion nous avait appris à aimer et à protéger, sont tués sans pitié dans deux arrondissements de la Gironde; que l'on en juge par le passage suivant d'un discours prononcé au Comice de Saint-Emilien, le ऽ octobre 1873, par Son Eminence le Cardinal de Bordeaux.

" Grâce à l'obligeance de M. Daleau qui a fourni à ce sujet de précieux renseignements, je puis avec confiance communiquer les chiffres auxquels s'élève la destruction des hirondelles dans quelques-unes de nos localités.

"Dans les grands palus de Blaye.....

"Dans les palus de St-Ciers-Lalande... $\quad 200,000$

"Dans les palus de Bourg.........

"Aux environs de Bourg......... $\quad \mathbf{4 , 0 0 0}$

"Dans les marais de Magrine....... 3 . 3̋,000

"Dans les marais d'Ambès......... 180,000

"Aux environs de St-André-de-Cubzac 1,つ00

"A Gauriaguet................ $\quad 1,500$

"A Sainte-Foix-la-Grande......... $\quad 222,000$

“Total......... 1,073,000 
"Il serait temps ", ajoute M. Dubalen, "que cette chasse stupide à des oiseaux si utiles fût définitivement et sérieusement prohibée. La meilleure des lois pour réprimer cet abus serait l'enseignement de l'ornithologie, au point de vue agricole, dans les écoles primaires des deux sexes ".

Cette chasse se fait au moyen de grands filets que l'on tend à la surface des prairies, et que l'on nomme pentes.

Dans la grotte de Bedeillac (Ariége), m'écrit M. Dubalen, on prend chaque année environ 20,000 hirondelles de fenètre (chelidon urbica).

Il est à remarquer que dans les départements du nord on ne fait pas la guerre à l'hirondelle. Plusieurs arrêtés préfectoraux prohibent cette chasse ; ainsi l'article 11 d'un arrêté de Meurthe en date du 20 décembre 1861 porte ce qui suit : " La chasse aux hirondelles par quelque mode que ce soit, est prohibée d'une manière absolue ".

Et maintenant comment la réhabilitation des oiseaux de passage n'est-elle pas entreprise et pour.suivie partout? L'indignation n'est-elle pas à son comble? Beaucoup d'hommes ne semblent-ils pas, quand il s'agit d'oiseaux, pris de vertige ou de folie? Devant la leçon sévère des faits, la société n'est-elle pas assez instruite? En face d'un incendie qui se propage reste-t-on les bras croisés?

Je reçois à l'instant, 15 novembre 1873 , de Soll Eminence le Cardinal de Bordeaux une lettre aussi paternelle que savante, et je transcris le passage suivant, comme couronnement naturel de mon chapitre :

"Continuez, Monsieur, à prendre la défense des 
hôtes de nos forêts, de nos vergers et de nos bosquets. Ils sont si désintéressés, si prêts toujours à être dévoués pour nous, le jour, la nuit, par le froid, par la chaleur, quelles que soient les intempéries de la saison. En ajoutant aux piéges et à tous les engins inventés pour leur destruction, le déboisement des montagnes, on semble vouloir prouver qu'à tout prix il faut se débarrasser de ces êtres bienfaisants. A nous de réagir. Il importe au plus haut point, non-seulement de s'opposer à leur disparition, mais encore de prendre des mesures pour les attirer dans notre zone et les fixer sur notre sol en facilitant leur reproduction ".

Ce chaleureux appel d'une voix si autorisée; je suis heureux de le répéter aux ornithologistes et à tous ceux qui aiment leur pays.

III.

\section{De quelques principes d'équité et de droit} invoqués par les tendeurs.

$\S 1^{\mathrm{er}}$. DE L'Égalité DEVANT LA LOI.

Je crois avoir démontré dans mon Mémoire publié par l'Académie de Reims, que la chasse des tendues n'est pas conforme à l'esprit de notre législation, et que celle-ci s'est inspirée du droit naturel. Examinons encore quelques objections faites à ce sujet.

C'est, dit-on, en se prévalant surtout de l'égalite. devant la loi, que les tendeurs ont obtenu le der- 
nier arrêté prefectoral de la Haute-viarne daté du 7 octobre 187 .

En fait, voici ce qui s'est passé. Malgré le rapport de M. Ducuing, en date du 7 février 1874, et le renvoi de ce rapport par l'Assemblée législative aux Ministres de l'agriculture et de l'intérieur, malgrè diverses instructions ministérielles ayant pour objet la protection des oiseaux utiles, le préfet de la Meuse, cédant en cela à la pression du conseil général de ce département, a permis les tendues. Les tendeurs des départements de la Meurthe et des Vosges se sont alors autorisés de cet exemple pour demander à leurs préfets le rétablissement de ce genre de chasse, et ils l'ont obtenu. Les tendeurs de la Haute-Marne ont invoqué l'exemple de leurs voisins et viennent d'obtenir la même faveur.

L'argument dont se prévalent les tendeurs de la Haute-Marne, devait précisément empêcher Monsieur le préfet de Chaumont de céder à leurs désirs.

Nous savons, en effet, que pour la plupart les oiseaux de double passage régulier dans notre vallée de la Marne, sont attirés pendant une partie de l'hiver dans nos départements du Midi par la douceur relative de la température, et dans ceux du centre et de l'Ouest par le climat maritime. Beaucoup de sylvains passent des forêts sur les arbres et arbustes de la plaine et des vergers; en sorte que ces ouvriers ne sont pas simplement, comme quelques tendeurs affectent de le dire, du gibier de parc, de commune, de canton et même de département, mais bien encore et surtout des ouvriers interdépartementaux et internationaux.

Nous savons que nos hirondelles transportent 
leur industrie d'Europe en Afrique. Il serait donc équitable, du moment où dans la Haute-Marne on peut détruire les petits insectivores en très-grand nombre, sans pitié et sans reconnaissance pour les services qu'ils nous rendent, qu'on accordât ce droit à tous les départements où passent ces oiseaux; on arriverait au moins de cette façon à démontrer aux plus aveugles l'absurdité d'une pareille réglementation.

Le mal ne se faisant que dans quelques départements, les vides sont toujours en partie comblés par de nouveaux contingents qui viennent des autres. D'après les principes que nous avons exposés, il n'y a pas de doute à cet égard; et alors quelques tendeurs peuvent dire avec une apparence de raison : Voyez, la diminution des oiseaux n'est pas sensible chez nous.

Il serait beaucoup plus profitable à l'intérêt général et beaucoup plus juste d'invoquer contre les tendeurs l'argument qu'ils ont produit; ainsi Monsieur le Préfet de la Haute-Marne leur aurait dit: Nous avons en France 86 départements; dans 3 seulement les tendues sont permises; en nous autorisant de l'exemple de 83 départements, demandons que Monsieur le Ministre de l'intérieur intervienne conformément aux délibérations du Sénat du 27 juin 1861 et de l'Assemblée législative du 7 février 1874, et qu'il proscrive les tendues dans tous les départements.

Je suis heureux de dire qu'une délibération en ce sens a été prise par le Conseil général du département de la Marne. M. Margaine, un de ses membres et député, s'appuyant sur l'exemple donné par le 
département de la Meuse, a demandé, en 1873, le droit de tendre pour les chasseurs de la Marne. Après mûre délibération, sa proposition a été repoussée par la presque unanimité du Conseil (1).

(1) Séance du 28 août 1873. - Compte-rendu.

14. Margaine saisit, à propos de la pêche, l'occasion de demander à N. le préfet s'il ne lui serait pas possible d'autoriser, dans le département de la Marne, la chasse aux petits oiseaux, permise dans la Nerise.

iI. le Préfet. - Une foule de circulaires ministérielles recommandent aux préfets de protéger les petits oiseaux, qui sont d'utiles auxiliaires de l'agriculture.

M. Margaine. - Encore faudrait-il prendre dans tous les départements des mesures uniformes.

M. Ponsard, président du comice départemental de la Marne, demande énergiquement le maintien de la prohibition dans ce département.

M. le Président. - Cette discussion doit éclairer suffisamment M. le préfet sur les intentions du conseil général. Nous le prions d'en tenir compte autant qu'il lui sera possible.

Arrêté du Préfet des Ardennes, en date du 24 mars 1862.

Art. 18. - La chasse aux oiseaux avec filets, lacets, sauterelles et gluaux, ainsi que le tir des hirondelles, sont interdits en tout temps. 11 n'y a d'exception que pour la bécasse et les échassiers.

Arrété du Préfet de l'Aube, en date du 30 janvier 1862.

Art. 11. - Les oiseaux de pays ou sédentaires et les oiseaux de passage autres que ceux désignés ci-dessus (oiseaux de proie) ne pourront être chassés que pendant le temps où la chasse est ouverte, et au fusil seulement.

Tous autres modes de chasse à ces oiseaux, tels que la pipée, les lacets, filets, sauterelles, raquettes, appeaux, appelants, chanterelles et engins quelconques sont formellement interdits.

\section{Arrété dus Préfet de la Meurthe en date du 20 décembre 1861.}

Article premier. - La chasse des oiseaux ne pourra plus se faire. daus le département de la Vleurthe, que pendant le temps oì la chasse ordinaire sera vuverte, et seulement à tir.

Art. 2. - Tous les autres procédés de chasse, tels que la pantière ou pantaine, le filet trainant, la tirasse, les sauterelles ou raquettes, lu 
Autant il me plaît d'étudier et d'apporter ma pari de recherches pour la solution de questions d'ordre social, autant il me répugne de m'occuper de personnalités. Les questions relatives à l'utilité des oiseaux sont nouvelles, spéciales et ardues. On comprend donc jusqu'à un certain point que M. X... ait tourmenté Honsieur le Préfet, pour obtenir un arrèté en faveur des tendeurs ; mais peutètre que demain, quand il sera mieux éclairé, il le priera de le rapporter. Toutefois, on ne doit pas. laisser subsister certains arguments qui ont été invoqués, assure-t-on, avec succès.

J'ai dit que le règlement de chasse aux petits oiseaux dans quelques départements, était au point de vue de l'équité un privilége constitué au profit des uns et au détriment des autres; or, dans le même ordre d'idées, on peut ajouter d'autres considérations d'une certaine gravité.

Il y a deux ans, en passant dans un bois du département de la Meuse, je rencontrai un pauvre diable qui venait de dénicher cinq grives. Je lui fis

pipée, les gluaux, les lacets ou collets, soit de pied, soit suspendus, sont formellement interdits.

En 1875, les tendues ont été de nouveau permises.

Arrêté du Préfet de Seine-et-Marne, en date du 15 juillet 1874.

Art. 9. - Est interdite, en tout temps, la destruction des petits oiseaux, par quelque moyen que ce soit.

Arrété du Préfet de l'Aisne, en date du 29 janvier 1867.

Art. 10. - La chasse aux oiseaux, avec filets, chanterelles, et gluaux, est interdite en tout temps.

Vosges. - Arrété d'ouverture de la chasse en $1875^{\circ}$

Art. 6. - Reproduction de l'art. 5 de l'arrêté du 1er août 1874, aunsi conçu : la chasse aux petits oiseaux est interdite de toute autre manière qu'au tir.

En 1875 , les tendues ont été de nouveau permises. 
observer que cela n'était légal dans aucune nation d'Europe pas plus qu'en France, el que cette défense n'était établie que dans l'intérêt général. Les raisons que vous me donnez, me répondit-il en un patois très-pittoresque et intraduisible, ne me semblent pas mauvaises; cependant vous ne me ferez pas accroire que je fais plus de mal que les gros richards qui tous les jours vont chercher des cargaisons d'oiseaux dans leurs tendues.

Je suppose que ces paroles n'ont pas besoin de commentaire.

Il faut bien le reconnaître, il est de l'essence d'une loi d'être la même pour tous à tous les étages de la société. S'il est de l'intérêt général de protéger les oiseaux les plus utiles, il faut ne tolérer en fait de destruction rien de ce qui est excessif, pas plus les tendues que le dénichage.

En rétablissant en ce moment les tendues, on crée desanomalies fort gênantes ; comment, par exemple, recommander dans une école la protection de l'oiseau et de son nid, quand en sortant de classe les enfants pourront savoir que ces oiseaux seront pris par milliers dans des raquettes ? Toutes les distinctions possibles arriveront-elles à persuader que l'arrêté de M. le Préfet n'est pas une déviation de l'enseignement de l'école ?

L'an dernier, à la demande du comice agricole de Saint-Dizier présidé par M. le vicomte Charles de Hédouville et de M. l'inspecteur des écoles de Chaumont, j'ai fait aux instituteurs du canton de SaintDizier, des entretiens sur l'utilité des oiseaux; ces Messieurs faisaient, le jeudi, par des chaleurs excessives, de longs et très-pénibles déplacements ; en 
reproduisant cet enseignement ils ont déployé un très-grand zèle et sont arrivés à des résultats inespérés; aussi le comice agricole a beaucoup regretté de ne pouvoir les récompenser tous. Toutefois des médailles et des primes ont été données aux plus méritants, et des écoliers ont reçu des livrets de caisse d'épargne.

Le comice a même décidé qu'il continuerait cette bonne ouvre.

II. le sous-directeur de l'agriculture m’a écrit plus tard qu'il trouvait utile et opportun d'introduire cet enseignement dans toutes les écoles agricoles de la région de l'Est.

Des sociétés protectrices des oiseaux ont été formées dans chaque école, et, d'après leurs registres, un grand nombre denids ont été connus et protégés. Dans la seule école de Roches-sur-Marne, et sousla direction de son instituteur, M. Dallemagne, les écoliers ont connu et protégé 192 nids qui ont fourni 8 วั oiseaux.

Eh bien! dans ces sociétés de protecteurs qui, sans instruction 'et livrés à leurs instincts, formeraient des sociétés de dénicheurs et de braconniers, comment justifier le privilége que se trouvent avoir les tendeurs du département de la Haute-Marne ? Car enfin ces oiseaux rendent des services dans un grand nombre de communeset de départements, non-seulement dans les forêts, mais encore dans les plantations de la plaine et des jardins, aux pauvres et aux riches, à tout le monde, et un seul tendeur en prendra par milliers! M. X.... écrivait dans le journal La Haute-Marne, $\mathrm{n}^{\circ}$ du 27 octobre 1875, qu'il en avait pris en 25 ans cent mille! 


\section{§ 2. - RESTRICTION DU MODE DE TENDUES.}

Pour donner satisfaction aux réclamations des assemblées législatives et aux instructions ministérielles, on a cherché par certaines restrictions à atténuer les mauvais effets de la tendue. Par exemple, on a imposé de ne mettre au lacet que deux crins, au lieu d'un plus grand nombre; ainsi les perdrix et les bécasses ont des chances d'échapper quand la loi est exécutée ; on a même interdit le lacet qui est, comme on le sait, destiné aux plus gros oiseaux. Il en est résulté que l'action du tendeur s'est de plus en plus concentrée sur la chasse aux petits et très-petits insectivores.

Disons bien haut que ces restrictions ne sont qu'un subterfuge impuissant dont on couvre un abus nuisible à l'intérêt publıc.

\section{§ 3. - LA TENDUE CONSIDÉRÉE COMME QUESTION ÉLEGTORALE.}

Un conseiller général de la Haute-Marne, avec lequel je m'entretenais dernièrement de ces questions, me répondit: que les tendeurs de certains cantons avaient déclaré qu'aux prochaines élections ils voteraient contre leurs conseillers et contre leurs députés, qu'ainsi la tendue était devenue un piége à élection, et que la question d'économie rurale se transformait, jusqu'à un certain point, en une question électorale et même gouvernementale. Il est d'ailleurs à remarquer que les tendeurs jouissent en général d'une certaine position sociale, qu'au 
moment des élections ils sont souvent consultes el (jue quelques-uns s'en mêlent activement.

Cette variété du mandat impératif n'a pas été sans donner quelques inquiétudes à plusieurs ; on aurait dû, en s'inspirant des délibérations du Sénat et de l'Assemblée législative, et des rapports à l'appui, essayer de démontrer aux réclamants que la chasse excessive des tendues est contraire à l'intérêt général et qu'elle n'est pas sans donner des goûts de dénichage et de braconnage au grand préjudice futur et certain de la chasse en plaine et au bois. On a préféré aller demander à M. le Préfet d'autoriser ce genre de chasse. En ne refusant pas, M. le Préfet a cru assurément donner satisfaction à un intérêt légitime et éviter un conflit.

Eh bien! je recommande aux solliciteurs deux passages du rapport de M. Bonjean.

$1^{\circ}$ Page 17. - "Ces auxiliaires indispensables, ces amis et ces alliés fidèles, l'homme reconnaissant les aura sans doute pris sous sa recommandation spéciale; il se sera appliqué à détruire les espèces ennemies qui leur font la guerre, l'oiseau de proie qui les saisit au vol, la couleuvre qui se glisse dans le nid pour y dévorer la couvée et souvent la mère avec ses petits... non, comme s'il voulait justifier une fois de plus cette apostrophe du fabuliste:

\footnotetext{
...... trouve bon qu'avec franchise,

En mourant au moins je te dise,

Que le symbole des ingrats,

Ce n'est point le serpent, c'est l'homme.
}

"C'est l'hommequi, par un étrange aveuglement, se montre le plus terrible ennemi de ces douces et 
utiles créatures! Plus cruel que le milan et l'épervier qui tuent pour se nourrir, lui, tue pour le seul plaisir de détruire.

"Le fusil n'est pas assez meurtrier, on le réserve d'ailleurs pour un plus noble gibier. C'est avec une multitude d'engins, filets, gluaux, collets, raquettes, sauterelles, etc. qu'il poursuit, avec une rage aveugle, ces amis aussi charmants qu'indispensables que la bonté de la Providence lui avait accordés.

"Je vous épargnerai, Messieurs, la description de ces chasses barbares. Il en est qui soulèvent le cœur de dégoût et d'horreur, la raquette ou sauterelle, par exemple, où la victime, ses pauvres petits os brisés par le piége, expire d'épuisement et de souffrances, après plusieurs heures d'agonie.

"Page 26. - Il ne faut pas se le dissimuler, les réformes proposées par les pétitionnaires vont heurter bien des préjugés, bien des habitudes invétérées en certaines parties du pays. Ne conviendraitil pas que la persuasion accompagnât ou mème précédât les moyens de coercition?"

§ 4. - DES TENDUES COMME QUESTION INTERNaTIONALE.

Si j'en crois la lettre du journal La Haute-Mame que j’ai dejjà citée, la question des tendues serait même devenue une question internationale d'une certaine gravité. On y lit : "D'ailleurs la chasse de ces petits oiseaux pris aux tendues n'est réellement fructueuse et avantageuse qu'au moment des passages qui nous viennent d'Allemagne où les tenducs sont permises.

"C'es! ce dernier motif qui a déterminé IIM. les 
Préfets des Vosges et de la Meuse à autoriser dans leur département respectif cette innocente récréation.

"Par conséquent M. le préfet de la Haute-Marne, en prenant son arrêté du 7 octobre dernier, qui permet la chasse des petits oiscaux, pour répondre au vœu bien légitime du conseil général, loin de mériter un blâme, a accompli envers notre pays un acte de justice dont le louent et le remercient sineèrement tous les tendeurs de raquettes des cantons d'Andelot, Saint-Blin et Bourmont.

"M. X."

I xaminons la valeur de cet argument.

On sait qu'en Allemagne des mesures nombreuses et très-sévères ont été prises pour la protection des oiseaux utiles (1); comment expliquer que dans l'Alsace-Lorraine, les Allemands aient accordé le privilége de faire des tendues? serait-ce parce que le département de la Meuse ayant rétabli les tendues aussitôt la paix faite, ils ont voulu accorder a ux annexés un semblant de compensation, de petits os à ronger?

Toujours est-il que dans cette région de l'Europe qui est la nôtre, la législation donne de singuliers signes d'incapacité ou d'impuissance.

Pour nous en rendre compte, supposons, en effet, qu'en septambre 187\%, un rouge-gorge soit parti

(1) Rapport Bonjean. - Nole le la fin. Le ministre du royaume de Prusse a adressé aux instituteurs une circulaire destinée à prévenir la destruction des œufs et des oiseaux utiles (Geoffroy Saint-Hilaire, De l'acclimatation, p. 120). Des lois protectrices des oiseaux ont élé portées en divers Etats de l'Allemagne, notamment dans la Hesse, le Wurtemberg, ld Saxe, elc. (Tschudi, p. 28.) 
de Hollande pour aller hiverner dans le midi de la France (la chose n'est pas rare), et qu'il ait traversé la Belgique, le département de la Meuse ou l'AlsaceLorraine, les Vosges et la Haute-Saône.

Pendant ses étapes en Belgique il aura pu s'arrêter à loisir partout où il aura trouvé un travail abondant et rémunérateur, rendre des visites à un bûcheron dans la forêt, à un pâtre le long d'une haie, et même à un citadin dans son jardin et sous ses fenêtres. Certes, il se sera laissé aller à fredonner son joli chant d'automne si doux, si gracieux et si sympathique.

Mais il a voyagé avec une espèce de passe-port Belge. Nous trouvons, en effet, dans la législation de ce pays les dispositions suivantes d'une ordonnance royale du 21 avril 1873 :

“ LÉopold II, roi des Belges;

"Vu la loi du 29 mars 1873 qui autorise le gouvernement à prévenir par un règlement d'administration générale la destruction des oiseaux insectivores;

"Vu la loi du 26 février 1846 ;

"Vu l'article 67 de la constitution;

"Sur la proposition de notre ministre de l'Intérieur;

"Nous avons arrêté et arrêtons:

"Art. 1 ${ }^{\mathrm{er}}$. - Il est défendu de prendre, de tuer ou de détruire, d'exposer en vente, de vendre, d'acheter, de transporter ou de colporter les oiseaux insectivores, ainsi quc leurs œufs ou couvées ;

"Art. 2. - Sont considérés comme oiseaux insectivores: 
" $1^{\circ}$ En tout temps, les espèces désignées ci-après:

"L'accenteur-mouchet ou traine-buissons, les fauvettes, les gobe-mouches ou bec-figues, le grimpereau, les hirondelles, les hoche-queue, bergeronnettes ou lavandières, l'hyppolaïs ou contrefaisant, les mésanges, les pouillots ou becs-fins, le roitelet huppé, le rossignol, le rouge-gorge, le rouge-queue tithys et le rossignol de muraille, la sittelle ou torchepot, les traquets tariers et motteux, le troglodyte ou roitelet.

" $2^{\circ}$ Pendant la chasse oì la perdrix n'est pas autorisée; toutes espèces d'oiseaux à l'état sauvage, sauf quelques exceptions relatives aux oiseaux de proie $)$.

Ne dirait-on pas que cette ordonnance a été inspirée au roi des Belges par le savant rapport de M. Bonjean?

"Mais incontestablement au premier rang, pour les services qu'ils nous rendent, viennent tous les oiseaux purement insectivores : les grimpereaux, le pic-vert, l'engoulevent, le coucou, les différentes variétés d'hirondelles, mais surtout ces charmants musiciens des champs, tous ces insectivores vulgairement désignés sous les expressions collectives de petits-pieds ou becs-fins : rossignols, faurettes, traquets, rouges-gorges, rouges-queues, bergeronnettes, pipits, pouillots, roitelets et le troglodyte, cet ami des chaumières, qui tous à l'envi nous rendent d'inappréciables services, services aussi gratuits que mal récompensés, parce qu'on ne s'en fait pas une idée suffisamment exacte (1)". 
M. Ducuing a conclu dans le même sens.

"La chasse aux espèces utiles doit être interdite par tout autre engin que le fusil.

"Doivent ètre déclarés espèces utiles tous les oiseaux insectivores, et notamment ceux dont la nomenclature suit : l'hirondelle, l'écorcheur, le gobemouches, le traquet, l'alouette, le rossignol, les becs-fins de toutes les variétés, le bruant, la fauvette, le troglodyte, le roitelet, la mésange, la bergeronnette, le chardonneret, le bouvreuil, le moineau, l'engoulevent, la sittelle, le grimpereau, la huppe, le pic, le torcol et l'étourneau, etc. La chasse au corbeau sera interdite ou tolérée suivant la région (1)".

Grâce donc à la législation belge, notre rougegorge arrive tout guilleret jusqu'aux douanes françaises ou allemandes, mais alors son attention est attirée par des scènes bien peu rassurantes. A ses regards apparaissent comme autant de potences des milliers et des milliers de raquettes. Pris dans ces engins meurtriers, des rouges-gorges se débattent pendant de longues heures en attendant qu'on leur torde le cou.

Sont-ce des contrebandiers? Non? Ont-ils commis quelques crimes dans nos départements de la frontière et dans l'Alsace-Lorraine? Aucun.

Supposons même qu'une bonne fée ait donné à l'un de ces rouges-gorges une forme humaine, il obtiendrait sans doute beaucoup de récompenses dans notre société française.

Dans une salle d'asile il aurait le prix de pro-

1) Rupport Ducuing, a la fin. 
preté el d'appétit, et dans un pensionnat de demoiselles celui de belle tenue ; car il est joli, gracieux, sa robe d'un gris modeste est rehaussée d'une collerette empourprée et éclatante, ce qui lui a valu le nom de rouge-gorge. Perché sur une branche de buisson, comme sur un piédestal, enguirlandé de verdures, il apparaît parfoís comme pour charmer les regards d'un artiste, pour inspirer une Rosa Bonheur.

Dans un conservatoire de musique ne concourrait-il pas avec succès? Dans son chant l'on trouve tour à tour les sons doux et veloutés de la flûte, les pénétrantes vibrations des hauts-bois et les accents émus de la voix. Il semble se complaire loin des trivialités de la musique. Il chante les joies de la famille, et, à n'en pas douter, les beautés de la création, le rayon du soleil, le beau ciel, la verdure et les fleurs; comme notre admirable virtuose de l'hiver, le troglodyte, il gazouille encore sous les voûtes et les ogives de neige.

Dans un comice agricole il obtiendrait une médaille de vermeil. Il a 18 ans d'âge et de bons services; 32 fois dans sa vie il a traversé la Hollande, la Belgique et la France; il a parcouru des milliers de kilomètres, pénétré et fureté dans les retraites les plus inconnues des forêts, des bosquets et des jardins. Aussi il a détruit des milliards d'insectes qui, en restant ou en devenant surabondants, auraient gaspillé de précieuses richesses agricoles (1). Ces innombrables ennemis il les a im-

(1) En examinant le contenu d'estomacs que javais soumis à son appréciation, M. Godron n'a trouvé que des larves d'insectes, des débris de petits coléoptères, des fragments de perce-oreilles. J'ai vil tans 
médiatement convertis en guano qu'il a semé partout. Toujours il a été le premier levé et le dernier couché. En fait de cabaret il n'a connu que la fontaine et le ruisseau. En dehors de ses repas il n'a guère ouvert le bec que pour édifier son nid ou pour chanter.

Sa conduite à l'égard de sa famille et à l'égard des hommes a été particulièrement louable.

Il y a de cela dix-huit ans, en Hollande, dans un nid de mousse à ciel de verdure, naissaient sept tout petits enfants; quand vinrent les migrations d'automne, toute la famille partit, notre jeune rougegorge, qui en était, fit alors son premier tour de France, il accomplit ses devoirs en toute occasion et retourna au printemps dans sa patrie.

Depuis 1820 , il compta en 17 fois 65 petits ; ce que lui coûtèrent les tribulations de la famille, personne ne le saura jamais. De ces chers enfants beaucoup lui furent mangés.

De plus, le rouge-gorge est par excellence un ami de l'homme, c'est chez lui une qualité tellement dominante que tous les auteurs se plaisent à la lui reconnaître; ils ont constaté qu'il s'approche des

d'autres des écailles de jeunes escargols. Un mémoire récompensé par la société d'agriculture, commerce, science et arts de la Marne, et produit par II. Deleur, mentionne encore comme nourriture de cet oiseau les insectes dont les noms suivent :

Anthomyie des oignons (anthomyia ceparum), puceron du prunier (aphis pruni), pyrale blanc de céruse (glyphiptera cerusana), mouche $(a)$ (musca domestica), pyrale des bourgcons du pin (coccyx turionana), tenthrède humérale (tentredo humeralis), puceron du pommier (aphis mali), teigne hémérobe (coleophora hemerobiella) tipule des potagers (b) (stipula olevacea).

(a) On compto 24 espèces de mouches ordinaires.

(b) Les tipules pondent plus de 300 oufs on une seulo portéc. 
habitations en hiver, qu'il pénètre mème dans les maisons et dans les chaumières; aussi M. Gerbe, d'après Blyth, le nomme-t-il rouge-gorge familier, rubecula familiaris.

Si, en cheminant dans la forèt, il rencontre un bûcheron, un charbonnier, il aime à s'arrêter et a s'approcher de lui, et à lui faire de gracieuses minauderies. De même que le vent apporte de l'océan la goutte d'eau qui rafraîchit la fleur desséchée, et qu'un rayon de lumière et de chaleur part du soleil pour raviver la séve du chêne endormie dans les ténèbres et le froid de la nuit, de mème au plus fort de l'hiver et quand les arbres plient sous le poids de la neige, le rouge-gorge vient offrir au cœur de l'ouvrier de bois un regard d'ami, comme un sourire de la Providence.

"Une vieille légende bretonne raconte que le rouge-gorge accompagna Jésus-Christ sur le Calvaire, chercha à le consoler par son chant et détacha une épine de la couronne du divin Rédempteur pouradoucir, autantqu'il le pouvait,'ses so uffrances. Afin de récompenser sa courageuse sympathie, Dieu laissa sur la poitrine du rouge-gorge l'empreinte d'une goutte de son sang divin, et cet oiseau reçut alors la mission de s'attacher aux pas de ceux qui travaillent et qui souffrent, pour continuer ainsi son rôle d'ami et de consolateur (1)".

Ainsi donc le dévouement du rouge-gorge pour ses enfants et ses nourrissons, ses vives sympathies pour les hommes, surtout pour les plus humbles et pour ceux qui souffrent, ont été très-remarquées

(1) il. Vincelot. 
par les savants et par les chrétiens, etpourraient lui valoir plus d'une recommandation.

Mais, il faut le reconnaître, les bonnes fées, dont j'ai parlé, sont de plus en plus rares, et les qualités qui viennent d'attirer notre attention et que la société aime à louer, à récompenser et à proclamer comme de nobles exemples chez les hommes, appartiennent à un tout petit être emplumé, sans qu'il s'attende à récompense.

Au moins, tendeur, et c'est là que je voulais en venir, laisse-le donc vivre; car, tu le vois, le rougegorge a sa place marquée dans les ateliers, dans les musées, dans les concerts et dans les temples de la nature, et il me semble que pour persister à ne pas le reconnaître, il faut être d'un incurable aveuglement d'estomac ; étudie et protège les oiseaux, tu jouiras de promenades hygiéniques, et de plus tu seras porté à méditer sur les merveilleuses harmonies dont les oiseaux sont une des plus belles expressions. Tu seras à la source des grandes idées et des grandes convictions, celles qui donnent la force et le courage.

Mais revenons à notre rouge-gorge.

Supposons qu'il a été assez heureux pour échapper à toutes les potences de la Meuse, des Vosges et de la Haute-Marne, il met le pied dans le département de la Haute-Saône. A son grand étonnement et à son extrême contentement il ne voit plus rien de sinistre, et il peut, sans de continuelles alarmes, se laisser aller au cours naturel de sa vie. - l'explication de ce fait se trouve dans un arrêté de M. le préfet de la Haute-Saône pour 1876.

"Art. 3. - La destruction au fusil, comme par 
tout autre mode de chasse des pelits oiseaux proprement dits, essentiellement insectivores, qu'ils soient de passage ou non, est formellement interdite. Une seule exception est établie en ce qui concerne les alouettes que l'on peut chasser au fusil à l'aide du miroir. En outre, des gratifications de $8,10,15$, et 25 francs sont accordées aux gardes qui auront dressé des procès-verbaux, suivis de condamnations, pour divers délits de cliasse, et notamment pour les lacets et la destruction des nids. Le gibier pris aux lacets peut être saisi et donner lieu à une condamnation ".

Il me semble que ces contradictions de la législation humaine et internationale, qui disent oui et non dans la mème question, ne sont pas faites pour inspirer le respect de la loi et la considération des législateurs.

La plupart des oiseaux ne sont-ils pas avant tout des professeurs et des ouvriers que la Providence envoie à toutes les nations, pour le plus grand bien de tous, des pauvres et des riches, de la vie matérielle, morale et intellectuelle? Pourquoi ne seraient-ils pas accueillis partout avec la même bienveillance qu'en Belgique et dans les départements de la Haute-Saône et de la Marne?

Quand bien même il nous en viendrait d'Allemagne, est-ce que beaucoup d'entre eux ne sont pas pour l'agriculture française des auxiliaires de l'automne, du printemps et souvent de l'hiver? Ce n'est pas avec cette guerre à coups d'épingles, la guerre des raquettes, que nous affaiblirons la Prusse. Ce n'est pas avec des brocheltes à la Lucullus que nous relèverons les caractères. Laissons 
donc ces chers et admirables oiseaux accomplir la tâche que dans notre intérêt Dieu leur a assignée. Qu'ils aillent chaque année chanter en Allemagne l'hospitalité de la France, qu'à chaque printemps ils aillent redire aux Alsaciens et aux Lorrains que notre patrie a toujours pour ses enfants un cœur de mère.

En fait de droit international, même quand il s'agit de tendues, aimons à ne proclamer et à ne suivre que les principes de l'équité et de la justice.

Il est à désirer, ainsi que nous l'avons écrit plusieurs fois, que les peuples interviennent pour protéger efficacement les oiseaux serviteurs et pour adopter à ce sujet des règlements communs.

Ce serait pour la France un bonheur de prendre l'initiative d'un congrès dans lequel seraient établie une carte ornithologique d'Europe et préparés les documents nécessaires pour cette spécialité de législation.

En attendant, et pour faciliter les voies, donnons au moins le bon exemple. 


\section{CONCLUSION.}

Nous en avons fini, je l'espère, avec les objections de quelques tendeurs; elles ont eu au moins le mérite de nous affermir dans nos convictions. Aussi je m'explique ce passage d'un rapport de M. Bonjean, page 20 :

"Le mal est grand encore une fois, le danger imminent; il faut des remèdes prompts et énergiques... Voilà ce que vous crient les honorables pétitionnaires et, avec eux, nombre de conseils généraux, ainsi que les sociétés de tout genre qui s'occupent, à des titres divers, d'agriculture et de zoologie. C'est ce que vous répètent, avec un accord chaque jour plus unanime et plus pressant, les naturalistes et les agriculteurs les plus distingués qui, par état ou par vocation, se sont occupés de celte question. MM. Geoffroy Saint-Hilaire, FlorentPrévost, Saac, Gloger, Koechlin, Dumast, JonyuieresAntonelle, Chatel, Gadebled, Valserres et tant d'autres dont nous n'avons été, en ce rapport, que l'écho très-affaibli ».

M. Ducuing ajoute que son rapport est base sur les réponses collectives émanant de 63 sociétes ou comices agricoles de toutes les régions de la France.

En résumé, il nous semble de toute évidence que la chasse à la tendue est aussi contraire à l'intérêt gúnéral qu'à l'esprit de nos lois. 
Elle est moins tolérable qu'autrefois, car elle levient bien vite plus générale et plus destructive, elle sert d'excuse ou de prétexte aux braconniers, qui dénichent et qui font des tendues volantes dans les forêts en été et près des habitations pendant les neiges, enfin elle est en trop flagrante contradiction avec l'enseignement que l'on commence à donner dans les écoles sur l'utilité des oiseaux.

Il importe donc que les assemblées législatives, le pouvoir exécutif, les conseils généraux, les sociètés savantes et agricoles interviennent à nouveau pour l'interdire.

Il y a une intervention qu'on ne peut trop recommander, elle consiste à démontrer aux chasseurs, aux conseillers généraux et à leurs électeurs que la voix, qui depuis quelque temps s'élève en faveur des oiseaux, est la voix de la science, de la morale, de l'esthétique et de la richesse.

J'ai déjà eu l'extrême satisfaction d'apprendre que, malgré l'insuffisance de mes écrits, j'avais eonverti des hommes d'une grande valeur et qu'ils avaient cessé de pratiquer ce genre de chasse. Je pourrais citer les noms d'un Président de Comice, de conseillers généraux et de tendeurs passionnés.

Ayons donc confiance dans le triomphe de la vérité. D'autres chasseurs ne demandent que d'être convaincus pour brûler leurs raquettes.

Dans un précédent ouvrage, nous avons établi les différences qui existent entre les oiseaux-gibier et les oiseaux-serviteurs. Il est facile de voir que la présente étude se rapporte à ces derniers. 


\title{
TABLE DES MATIÈRES
}

\author{
PREMIÉRE PARTIE
}

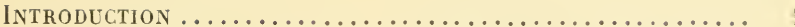

I. Du droit de chasse :

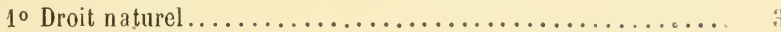

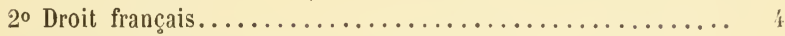

$3^{\circ}$ De la législation relative aux oiseaux............. 9

II. Statistique de tendues....................... 14

III. Avantages de la tendue...................... 22

IV. Conséquences malheureuses de la tendue :

$1^{\circ}$ du point de vue des oiseaux sédentaires........... 23

20 Au point de vue des oiseaux de passage............. 27

$3^{\circ}$ Dommages résultant de la destruction excessive des oiseaux sédentaires et des oiseaux de passage, dans les bois, près des habitations, dans la plaine et sur les rives d'eaux......... 30

$4^{0}$ Proportion des pertes occasionnées par la destruction des petits insectivores; impossibilité d'y remédier.......... 32

$5^{\bullet}$ Réponses à quelques objections ................ 38

$6^{\circ}$ Effets de la tendue au point de vue moral ........... 40

$7^{\circ}$ Les oiseaux nous convient aux enseignements et aux nobles joies que l'on trouve dans la contemplation du beau ...... 42

Conclusion............................. 48

DEUXIËME PARTIE.

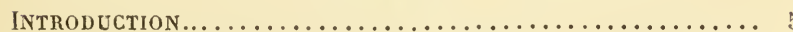

I. Les tendues détruisent, sans profit sérieux pour l'alimentation, les plus petits oiseaux insectivores. - Dommages qui en résultent.

II. Oiseaux de passage :

$\S 1 \mathrm{er}$. - De la répartition des oiseaux à la surface de la terre. Des migrations, de leurs causes, de leurs moyens, et de leurs effets utiles 
$\$ 2 .-$ Utilité des oiseaux de passage............... 80

§ 3 . - Intervention de l'homme en faveur des oiseaux de passage.................................. 85

III. - De quelques principes d'équité et de droit invoqués par les tendeurs :

$\$ 1$ er. - De l'égalité devant la loi ................ 93

$\S 2 .-$ Restriction du mode de tendues.............. 100

§ 3. - La tendue considérée comme question électorale..... 100

$\$ 4$ - Des tendues comme question internationale........ 102

Concuusion............................... 113 
.

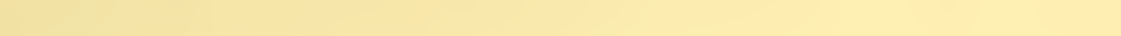

. 

